\title{
Heart
}

\section{Prognostic value of admission high-sensitivity troponin in patients with ST-elevation myocardial infarction.}

\begin{tabular}{|c|c|}
\hline Journal: & Heart \\
\hline Manuscript ID & heartjnl-2021-319225.R3 \\
\hline Article Type: & Original research \\
\hline $\begin{array}{r}\text { Date Submitted by the } \\
\text { Author: }\end{array}$ & 29-Aug-2021 \\
\hline Complete List of Authors: & $\begin{array}{l}\text { Coelho-Lima, Jose; Newcastle University } \\
\text { Georgiopoulos, George; University of Athens Medical School, } \\
\text { Hippokration Hospital, Athens, Greece, Cardiology } \\
\text { Ahmed, Javed; Freeman Hospital } \\
\text { Adil, Syeda; Royal Stoke University Hospital } \\
\text { Gaskin, David; Newcastle University } \\
\text { Bakogiannis, Constantinos; Newcastle University } \\
\text { Sopova, Kateryna; Newcastle University } \\
\text { Ahmed, Fareen; Freeman Hospital } \\
\text { Ahmed, Haaris; Freeman Hospital } \\
\text { Spray, Luke; Freeman Hospital } \\
\text { Richardson, Gavin; Newcastle University } \\
\text { Bagnall, Alan; Freeman Hospital, Department of Cardiology } \\
\text { Stellos, Konstantinos; Newcastle University } \\
\text { Stamatelopoulos, Kimon; National and Kapodistrian University of Athens } \\
\text { School of Health Sciences, Clinical Therapeutics } \\
\text { Spyridopoulos, Ioakim; Newcastle University, Institute of Human } \\
\text { Genetics }\end{array}$ \\
\hline Keywords: & $\begin{array}{l}\text { Myocardial Infarction < Coronary Artery Disease, Percutaneous Coronary } \\
\text { Intervention < Endovascular Procedures, Biomarkers < Risk Factors }\end{array}$ \\
\hline Abstract: & $\begin{array}{l}\text { Background and aim: Although the diagnostic usefulness of high- } \\
\text { sensitivity cardiac troponin T (hs-cTnT) is well established in ST-segment } \\
\text { elevation myocardial infarction (STEMI), its prognostic relevance in risk } \\
\text { stratification of STEMI patients remains obscure. This study sought to } \\
\text { determine the prognostic value of pre-reperfusion (admission) and post- } \\
\text { reperfusion (12h) hs-cTnT in STEMI patients treated with primary } \\
\text { percutaneous coronary intervention (PPCI). } \\
\text { Methods: Retrospective observational longitudinal study including } \\
\text { consecutive STEMI patients treated with PPCI at a university hospital in } \\
\text { the northeast of England. Hs-cTnT was measured at admission to the } \\
\text { catheterization laboratory and } 12 \mathrm{~h} \text { after PPCI. Clinical, procedural, and } \\
\text { laboratory data were prospectively collected during patient } \\
\text { hospitalisation (Jun/2010 - Dec/2014). Mortality data were obtained } \\
\text { from the UK Office of National Statistics. The study endpoints were in- } \\
\text { hospital and overall mortality. } \\
\text { Results: A total of } 3,113 \text { patients were included. Median follow-up was } \\
53 \text { months. Admission hs-cTnT }>515 \mathrm{ng} / \mathrm{L} \text { (4th quartile) was }\end{array}$ \\
\hline
\end{tabular}


independently associated with in-hospital mortality $(\mathrm{HR}=2.53$ per highest to lower quartiles; $95 \% \mathrm{CI}: 1.32-4.85 ; \mathrm{p}=0.005)$ after multivariable adjustment for a clinical model of mortality prediction. Likewise, admission hs-cTnT> $515 \mathrm{ng} / \mathrm{L}$ independently predicted overall mortality $(H R=1.27$ per highest to lower quartiles; $95 \% C I: 1.02-1.59 ; p=0.029)$. Admission hs-cTnT correctly reclassified risk for in-hospital death [net reclassification index $(\mathrm{NRI})=0.588 \%, \mathrm{p}<0.001)$ and overall mortality (NRI $=0.178 \%, p=0.001)$. Conversely, $12 \mathrm{~h}$ hs-cTnT was not independently associated with mortality.

Conclusion: Admission, but not $12 \mathrm{~h}$ post-reperfusion, hs-cTnT predicts mortality and improves risk stratification in the PPCI era. These results support a prognostic role for admission hs-cTnT whilst challenge the cost-effectiveness of routine $12 \mathrm{~h}$ hs-cTnT measurements in STEMI patients.

\section{SCHOLARONE Manuscripts}


I, the Submitting Author has the right to grant and does grant on behalf of all authors of the Work (as defined in the below author licence), an exclusive licence and/or a non-exclusive licence for contributions from authors who are: i) UK Crown employees; ii) where BMJ has agreed a CC-BY licence shall apply, and/or iii) in accordance with the terms applicable for US Federal Government officers or employees acting as part of their official duties; on a worldwide, perpetual, irrevocable, royalty-free basis to BMJ Publishing Group Ltd ("BMJ") its licensees and where the relevant Journal is co-owned by BMJ to the co-owners of the Journal, to publish the Work in this journal and any other BMJ products and to exploit all rights, as set out in our licence.

The Submitting Author accepts and understands that any supply made under these terms is made by BMJ to the Submitting Author unless you are acting as an employee on behalf of your employer or a postgraduate student of an affiliated institution which is paying any applicable article publishing charge ("APC") for Open Access articles. Where the Submitting Author wishes to make the Work available on an Open Access basis (and intends to pay the relevant APC), the terms of reuse of such Open Access shall be governed by a Creative Commons licence - details of these licences and which Creative Commons licence will apply to this Work are set out in our licence referred to above.

Other than as permitted in any relevant BMJ Author's Self Archiving Policies, I confirm this Work has not been accepted for publication elsewhere, is not being considered for publication elsewhere and does not duplicate material already published. I confirm all authors consent to publication of this Work and authorise the granting of this licence. 


\section{Prognostic value of admission high-sensitivity troponin in patients with ST-elevation}

\section{myocardial infarction}

Jose Coelho-Lima ${ }^{\#}$, Georgios Georgiopoulos\#, Javed Ahmed, Syeda E R Adil, David Gaskin, Constantinos Bakogiannis, Kateryna Sopova, Fareen Ahmed, Haaris Ahmed, Luke Spray, Gavin Richardson, Alan Bagnall, Konstantinos Stellos, Kimon Stamatelopoulos*, Ioakim Spyridopoulos* $(\bowtie)$

Jose Coelho-Lima, MD PhD, Cardiovascular Research Centre, Faculty of Medical Sciences, Newcastle University, Newcastle upon Tyne, United Kingdom, NE1 3BZ

Javed Ahmed, Consultant Interventional Cardiologist, Department of Cardiology, Freeman Hospital, Newcastle Hospitals NHS Foundation Trust, Newcastle Upon Tyne, United Kingdom, NE7 7DN

Georgios Georgiopoulos, Research Fellow, Department of Clinical Therapeutics, Alexandra Hospital, National and Kapodistrian University of Athens, Athens, 115 28, Greece

Syeda E R Adil, Physician, Respiratory unit, Royal Stoke University Hospital, Stoke-on-Trent, United Kingdom, ST4 6QG

David Gaskin, Medical Student, Cardiovascular Research Centre, Faculty of Medical Sciences, Newcastle University, Newcastle upon Tyne, United Kingdom, NE1 3BZ

Constantinos Bakogiannis, Research Fellow, Cardiovascular Research Centre, Faculty of Medical Sciences, Newcastle University, Newcastle upon Tyne, United Kingdom, NE1 3BZ

Kateryna Sopova, Research Fellow, Cardiovascular Research Centre, Faculty of Medical Sciences, Newcastle University, Newcastle upon Tyne, United Kingdom, NE1 3BZ

Fareen Ahmed, Medical Student, Department of Cardiology, Freeman Hospital, Newcastle Hospitals NHS Foundation Trust, Newcastle Upon Tyne, United Kingdom, NE7 7DN

Haaris Ahmed, Medical Student, Department of Cardiology, Freeman Hospital, Newcastle Hospitals NHS Foundation Trust, Newcastle Upon Tyne, United Kingdom, NE7 7DN

Luke Spray, Department of Cardiology, Freeman Hospital, Newcastle Hospitals NHS Foundation Trust, Newcastle Upon Tyne, United Kingdom, NE7 7DN

Gavin Richardson, Biosciences Institute, Cardiovascular biology and medicine, Newcastle University, Newcastle upon Tyne, United Kingdom, NE1 3BZ

Alan Bagnall, Consultant Interventional Cardiologist, Department of Cardiology, Freeman Hospital, Newcastle Hospitals NHS Foundation Trust, Newcastle Upon Tyne, United Kingdom, NE7 7DN

Konstantinos Stellos, Professor of Cardiology, Cardiovascular Research Centre, Faculty of Medical Sciences, Newcastle University, Newcastle upon Tyne, United Kingdom, NE1 3BZ

Kimon Stamatelopoulos, Professor, Department of Clinical Therapeutics, Alexandra Hospital, National and Kapodistrian University of Athens, Athens, 115 28, Greece

Ioakim Spyridopoulos, Professor of Cardiology, Consultant Interventional Cardiologist, Freeman Hospital, Chair of Cardiovascular Gerontology, Cardiovascular Research Centre, Faculty of Medical Sciences, Newcastle University, Newcastle upon Tyne, United Kingdom, NE1 3BZ 
Coelho-Lima et al.

\# contributed equally as first-authors

* contributed equally as senior authors

\author{
Word count: 2,999 \\ Number of references: 30 \\ Number of figures: 2 \\ Number of tables: 3
}

Corresponding author $(\triangle)$ :

Prof. Ioakim Spyridopoulos, MD, FRCP, FESC. Tel. +44-191-2418675.

Email: ioakim.spyridopoulos@newcastle.ac.uk 


\begin{abstract}
Background and aim: Although the diagnostic usefulness of high-sensitivity cardiac troponin $\mathrm{T}$ (hs-cTnT) is well established in ST-segment elevation myocardial infarction (STEMI), its prognostic relevance in risk stratification of STEMI patients remains obscure. This study sought to determine the prognostic value of pre-reperfusion (admission) and post-reperfusion (12h) hs-cTnT in STEMI patients treated with primary percutaneous coronary intervention (PPCI).

Methods: Retrospective observational longitudinal study including consecutive STEMI patients treated with PPCI at a university hospital in the northeast of England. Hs-cTnT was measured at admission to the catheterization laboratory and $12 \mathrm{~h}$ after PPCI. Clinical, procedural, and laboratory data were prospectively collected during patient hospitalisation (Jun/2010 - Dec/2014). Mortality data were obtained from the UK Office of National Statistics. The study endpoints were in-hospital and overall mortality.
\end{abstract}

Results: A total of 3,113 patients were included. Median follow-up was 53 months. Admission hs$\mathrm{cTnT}>515 \mathrm{ng} / \mathrm{L}$ ( $4^{\text {th }}$ quartile $)$ was independently associated with in-hospital mortality $(\mathrm{HR}=2.53$ per highest to lower quartiles; $95 \% \mathrm{CI}: 1.32-4.85 ; \mathrm{p}=0.005$ ) after multivariable adjustment for a clinical model of mortality prediction. Likewise, admission hs-cTnT $>515 \mathrm{ng} / \mathrm{L}$ independently predicted overall mortality ( $\mathrm{HR}=1.27$ per highest to lower quartiles; 95\%CI: $1.02-1.59 ; \mathrm{p}=0.029)$. Admission hs-cTnT correctly reclassified risk for in-hospital death [net reclassification index $(\mathrm{NRI})=0.588 \%, \mathrm{p}<0.001)$ and overall mortality $(\mathrm{NRI}=0.178 \%, \mathrm{p}=0.001)$. Conversely, $12 \mathrm{~h}$ hs-cTnT was not independently associated with mortality.

Conclusion: Admission, but not $12 \mathrm{~h}$ post-reperfusion, hs-cTnT predicts mortality and improves risk stratification in the PPCI era. These results support a prognostic role for admission hs-cTnT whilst challenge the cost-effectiveness of routine $12 \mathrm{~h}$ hs-cTnT measurements in STEMI patients.

Keywords: STEMI; primary PCI; risk stratification; mortality; cardiac troponin 


\section{Key Messages}

\section{What is already known about this subject?}

Troponin levels are routinely used in clinical practice for the diagnosis of myocardial infarction but the prognostic value of hs-cTnT assays in the era of PPCI is controversial.

\section{What does this study add?}

This study shows that hs-cTnT levels at admission to the catheterisation laboratory, but not hs$\mathrm{cTnT}$ routinely measured $12 \mathrm{~h}$ post-PPCI, predict mortality and improve risk stratification in patients with STEMI.

\section{How might this impact on clinical practice?}

These findings support a prognostic role for admission hs-cTnT but not for routine $12 \mathrm{~h}$ hs-cTnT measurements in STEMI patients.

Patient and public involvement: patients were not involved at any stage of this study. 


\section{Coelho-Lima et al.}

Pre-reperfusion hs-cTnT predicts mortality in STEMI

\section{Introduction}

Despite implementation of evidence-based therapy for ST-segment elevation myocardial infarction (STEMI), including primary percutaneous coronary intervention (PPCI), global short and longterm mortality rates (in-hospital: $7 \%-11 \% ; 1$ to 5 -year: $11 \%-23 \%$ ) remain elevated in this condition (1-3). These figures highlight the current need for risk algorithms that enable clinicians to precisely distinguish between STEMI patients at extreme high versus lower risk, which is crucial to guide secondary prevention strategies post-STEMI (4). In this context, circulating biomarkers that reflect the severity of pathological mechanisms associated with STEMI may act as integrating factors that, combined with traditional outcome predictors, could have a significant additive prognostic value in optimizing risk stratification with a view to improving long-term treatment strategies for STEMI patients.

High-sensitivity cardiac troponin (hs-cTn) assays are the gold-standard biomarkers to assess acute myocardial injury $(5,6)$. When coupled with clinical evidence of myocardial ischaemia, acute rise and/or fall of hs-cTn levels compose the criteria for the diagnosis of myocardial infarction $(5,6)$. Despite its ancillary diagnostic role, there is scarce and contradictory evidence examining the prognostic value of current hs-cTn assays in STEMI patients undergoing PPCI (7-11). Few studies with small cohorts suggest differential prognostic roles for pre- and post-reperfusion hs-cTn levels (7-11). Nonetheless direct comparisons between these two measurement time points have never been performed in large cohorts. We hypothesized that pre- and post-reperfusion hs-cTn levels may reflect distinct processes associated with myocardial injury and reperfusion and hence may provide different prognostic information. This study aimed to compare the prognostic relevance of admission and $12 \mathrm{~h}$ post-reperfusion hs-cTnT levels for mortality prediction and risk stratification in a large cohort of STEMI patients treated with PPCI. 


\section{Methods}

\section{Patient population}

Data from consecutive STEMI patients treated with PPCI at the Freeman Hospital (Newcastle upon Tyne, UK) between June 2010 and December 2014 were collected prospectively. Diagnosis of STEMI was based on the presence of chest pain suggestive of myocardial ischaemia lasting longer than 30 minutes accompanied by ST-segment elevation or new left bundle branch block on the ECG (6). Patients were considered for PPCI if they presented within $12 \mathrm{~h}$ of symptom onset. STEMI patients were given $300 \mathrm{mg}$ of aspirin and were transferred directly to the cardiac catheterization laboratory. On arrival, a loading dose of a second antiplatelet along with standard doses of heparin or bivalirudin were administered according to international guidelines (12). Glycoprotein (GP) IIb/IIIa inhibitors were administered by discretion of the operator during PPCI. When patients were admitted several times for PPCI, only data from their first presentation was included for analysis.

\section{Study design}

This was a retrospective longitudinal cohort study. The primary data source was the local coronary artery disease (CAD) database (Dendrite Clinical Systems, Ltd., Oxford, England, UK). The data are annually submitted to the National Institute for Cardiovascular Outcomes Research (NICOR) audit registry and are regularly validated. Baseline demographics and clinical parameters were prospectively collected at the end of each procedure by the attending physician. Post-procedural clinical data were updated on discharge by Freeman Hospital database managers.

Mortality data were provided by the Office of National Statistics, which records all deaths in the UK. The National Health Service (NHS) patient unique identification number (NHS number) available in the Office of National Statistics dataset was used to link mortality information to our database. The cut-off date for mortality assessment in every patient was the $20^{\text {th }}$ of June 2017 . The 
prognostic endpoints were (i) in-hospital mortality, defined by all-cause deaths during hospitalisation and (ii) overall all-cause mortality, which included in-hospital and post-hospital discharge deaths. This study complied with the Declaration of Helsinki.

\section{Cardiac troponin measurement}

Serum samples were obtained from arterial blood collected from the radial or femoral sheath on admission to the catheterization laboratory (immediately prior to PPCI) as well as from venous blood samples collected 12 hours post-PPCI. Cardiac troponin T was quantified with the Roche Elecsys hs-cTnT assay on the Cobas e601 module (Roche Diagnostics, United Kingdom). According to manufacturer information, the hs-cTnT assay has a limit of detection reported at 2.05 $\mathrm{ng} / \mathrm{L}$ and coefficient of variation $<10 \%$ at the $99^{\text {th }}$ percentile $(14 \mathrm{ng} / \mathrm{L})$.

\section{Statistical analysis}

Differences in distribution of baseline characteristics between survivors and non-survivors were assessed by t-test or Mann-Whitney U test for continuous variables and chi-square test for categorical variables. Patients were assigned to quartiles according to admission or $12 \mathrm{~h} \mathrm{hs-cTnT}$ levels. Comparisons in distributions of baseline variables between hs-cTnT quartile groups were performed with the Kruskal-Wallis test with Dunn's correction for multiple comparisons for continuous variables or with the Chi-square test for categorical variables. Survival distributions between distinct admission and $12 \mathrm{~h}$ hs-cTnT quartile groups were estimated by Kaplan-Meier survival analysis (log-rank test).

A core clinical model for prediction of overall mortality was determined by stepwise backwards multivariable Cox regression analysis. Clinical, biochemical, and peri-procedural variables were used to derive such model, many of which compose previously published or established risk prediction tools, such as the GRACE score $(13)(1,3)$ (Supplemental table 1). Variables that 


\section{Coelho-Lima et al.}

Pre-reperfusion hs-cTnT predicts mortality in STEMI

showed significant $(\mathrm{p}<0.05)$ association with mortality by multivariable Cox regression were selected to compose the prediction model (Supplemental table 1). Independent association between admission and $12 \mathrm{~h}$ hs-cTnT and the study endpoints was assessed by stepwise backwards multivariable Cox regression over the core prediction model. The percentage of missing values for the confounders included in the multivariable Cox regression analysis were all below $6 \%$

(Supplemental table 2). Only cases with complete data for all variables were included in the Cox regression analysis.

Proportional-hazards regression models with 3-knots restricted cubic splines (i.e. natural splines) (RCSs) of either admission hs-cTnT or $12 \mathrm{~h}$ hs-cTnT were implemented to model the association between hs-cTnT and the study endpoints without linearity assumptions (14). This approach sought to circumvent limitations associated with the categorization of a continuous variable whilst exploring non-linear relationships between hs-cTnT and the outcomes. Finally, the additive predictive value of hs-cTnT over core predictors of in-hospital and overall mortality was estimated by i) likelihood ratio tests for nested multivariable models and b) continuous net reclassification index (NRI). We used bootstrapping with 1,000 replicates to construct bias-corrected 95\% confidence intervals around the NRI estimate (15). All tests were two-tailed. Statistical analyses were performed by SPSS software v22.0 (IBM, New York, USA) or Stata package, version 16.0 (StataCorp, College Station, Texas, USA). Statistical significance was deemed at $\mathrm{p}<0.05$ unless stated otherwise. Detailed information about the proportional-hazards regression and doseresponse curves can be found in the Supplemental Methods. 


\section{Results}

\section{Admission and 12h hs-cTnT reflect distinct clinical risk profiles}

From the 3,408 consecutive patients, those who did not have admission hs-cTnT $(\mathrm{n}=195,5.7 \%)$, $12 \mathrm{~h}$ hs-cTnT $(\mathrm{n}=57,1.6 \%)$, or both $(\mathrm{n}=43,1.2 \%)$ quantified were excluded, resulting in a final cohort of 3,113 patients. Clinical and peri-procedural baseline characteristics of the study population are summarized in table $\mathbf{1}$. The distribution of parameters traditionally related to worse risk profile differed between admission and $12 \mathrm{~h}$ hs-cTnT quartile groups. Increasing admission hscTnT levels were associated with more frequent inter-hospital transfer than direct admission to the catheterization laboratory from ambulance $(\mathrm{p}<0.001)$ (Supplemental table 3). This was reflected by longer symptom-onset-to-reperfusion time $(\mathrm{p}<0.001)$ and door-to-balloon time $(\mathrm{p}=0.008)$, notably in the highest admission hs-cTnT quartile group (hs-cTnT $>515 \mathrm{ng} / \mathrm{L}$; Supplemental table 3). In addition, these patients presented with higher heart rate $(p<0.001)$, increased incidence of cardiogenic shock $(\mathrm{p}<0.001)$, and lower haemoglobin levels $(\mathrm{p}<0.001)$ (Supplemental table 3). Finally, in terms of peri-procedural parameters, greater use of femoral access $(p<0.001)$ and incidence of coronary slow flow phenomenon $(p=0.005)$ were observed with increasing admission hs-cTnT (Supplemental table 3). Consequently, the incidence of inhospital and overall mortality was significantly greater in the highest admission hs-cTnT quartile group (Supplemental table 3). In contrast, no difference in the distribution of these variables was observed among 12h hs-cTnT quartiles, except for cardiogenic shock (Supplemental table 4).

\section{Prognostic value of admission and $12 \mathrm{~h}$ hs-cTnT}

In-hospital mortality rate was 3\% $(\mathrm{n}=94$ deaths $)$ and overall mortality was $16.4 \%(\mathrm{n}=509$ deaths) at a median follow-up period of 53 months (interquartile range $37-68$ months)

(Supplemental table 3). Kaplan-Meier survival analysis revealed a significant association 
between increasing admission hs-cTnT quartiles and higher probability of in-hospital and overall mortality (Figures 1A and 1B). For $12 \mathrm{~h}$ hs-cTnT quartiles, there was no association with inhospital mortality but a significant correlation with overall mortality (Figures 1C and 1D). In addition, univariable Cox regression analysis showed that admission hs-cTnT levels $>515 \mathrm{ng} / \mathrm{L}$ ( $4^{\text {th }}$ quartile) were associated with higher risk of in-hospital and overall mortality (Table 2). In contrast, $12 \mathrm{~h}$ hs-cTnT levels $>5,221 \mathrm{ng} / \mathrm{L}$ ( $4^{\text {th }}$ quartile) were not associated with higher risk of inhospital mortality but conferred significantly higher risk of overall mortality (Table 2).

After adjustment for the core mortality prediction model including age, current smoking, diabetes mellitus, previous myocardial infarction, admission haemoglobin, admission creatinine, heart rate on admission, anterior myocardial infarction, administration of glycoprotein IIb/IIIa inhibitors, TIMI score 3 post-PPCI, and door-to-balloon time by multivariable Cox regression, admission hscTnT was an independent predictor of in-hospital mortality $(\mathrm{HR}=2.53$ per highest to lower quartiles, 95\% CI $=1.32-4.85, \mathrm{p}=0.005)$ (Table 2). Admission hs-cTnT was also independently associated with overall mortality $(\mathrm{HR}=1.27$ per highest to lower quartiles, $95 \% \mathrm{CI}=1.02-1.59$, $\mathrm{p}=0.029$ ) after adjusting for the core mortality prediction model (Table 2). Conversely, 12h hscTnT was not an independent predictor of overall mortality (Table 2).

\section{Dose-response relationship between levels of continuous hs-cTnT and study endpoints}

A non-linear association of circulating levels of admission and $12 \mathrm{~h}$ hs-cTnT with both in-hospital and overall mortality was observed (Figure 2). Interestingly, dose-response curve analysis, revealed distinct patterns of associations with mortality between admission and $12 \mathrm{~h}$ hs-cTnT

(Figure 2). In specific, admission hs-cTnT was consistently positively associated with in-hospital mortality (adjusted $H R=3.42$ for $80^{\text {th }}$ vs. $20^{\text {th }}$ percentiles, $95 \%$ CI $1.83-6.39, \mathrm{p}<0.001$; Figure 2A) after adjustment for the variables in the core model whereas $12 \mathrm{~h}$ hs-cTnT was not (adjusted $\mathrm{HR}=0.96$ for $80^{\text {th }}$ vs. $20^{\text {th }}$ percentiles, $95 \%$ CI $0.51-1.80, \mathrm{p}=0.663$; Figure 2 B). With regards to 
Coelho-Lima et al.

Pre-reperfusion hs-cTnT predicts mortality in STEMI

overall mortality, admission hs-cTnT (adjusted HR=1.32 for $80^{\text {th }}$ vs. $20^{\text {th }}$ percentiles, $95 \%$ CI $1.05-$ $1.65, \mathrm{p}=0.015$; Figure 2C) but not $12 \mathrm{~h}$ hs-cTnT (adjusted $\mathrm{HR}=0.87$ for $80^{\text {th }}$ vs. $20^{\text {th }}$ percentiles, 95\%CI 0.69-1.10, $\mathrm{p}=0.256$; Figure 2D) was significantly associated with increased risk after adjusting for the core clinical model of overall mortality prediction. Interestingly, $12 \mathrm{~h}$ hs-cTnT was inversely associated with overall mortality at low and medium concentrations [adjusted $\mathrm{HR}=$ 0.72 for $60^{\text {th }}$ (nadir) vs. $1^{\text {st }}$ percentile, $95 \%$ CI $0.57-0.91, p=0.006$; Figure 2D].

\section{Admission hs-cTnT confers incremental calibration and reclassification value over core predictive models of in-hospital and overall mortality}

Admission hs-cTnT conferred additive calibration (likelihood ratio test $\mathrm{p}<0.001$ ) and reclassification value (overall continuous $\mathrm{NRI}=0.588,95 \% \mathrm{CI} 0.278-0.903, \mathrm{p}<0.001$ ) over the core in-hospital mortality prediction model (Table 2). The reclassification value of admission hs-cTnT was driven by correctly reclassifying into lower risk patients who did not die across hospitalization (70.5\%) whereas $11.8 \%$ of patients who experienced the adverse outcome (i.e., in hospital mortality) were inappropriately reclassified into lower risk (Table 2). Similarly, admission hs-cTnT improved the goodness of fit of the core model (likelihood ratio test $\mathrm{p}=0.001$ ) for overall mortality and correctly reclassified patients without the events into lower risk (57.6\%) while a smaller fraction of patients who died were incorrectly classified (39.8\%, overall $\mathrm{NRI}=0.178,95 \%$ CI $0.037-0.311, \mathrm{p}=0.001$, Table 3 ). 


\section{Coelho-Lima et al.}

Pre-reperfusion hs-cTnT predicts mortality in STEMI

\section{Discussion}

This study main findings are that: (i) admission hs-cTnT was independently associated with both in-hospital and long-term mortality whilst $12 \mathrm{~h}$ hs-cTnT was not; (ii) admission hs-cTnT displayed a consistently positive dose-response association with mortality whereas $12 \mathrm{~h}$ hs-cTnT presented an inverse correlation with long-term mortality in low to medium concentrations; (iii) most importantly, addition of admission hs-cTnT to baseline clinical predictors of in-hospital and overall mortality improved the calibration of the best prognostic core model and correctly reclassified patients who did not die into lower risk, especially for in-hospital mortality.

The occurrence of STEMI confers a greater risk of subsequent major adverse cardiovascular events (MACE) and death. Accumulating evidence suggests that a more aggressive secondary prevention strategy post-acute coronary syndrome (ACS) is beneficial in terms of survival and reduction of ischaemic events (16-20). Risk stratification is fundamental to tailor secondary prevention strategies. To this end, several short and long-term mortality risk prediction models have been assessed in STEMI cohorts (21-23) but have not yet been incorporated into clinical guidelines (24). Given the significant unmet need for optimizing risk stratification in STEMI patients, the identification of markers that can provide incremental prognostic value over traditional outcome predictors is warranted.

In this study, we directly compared the prognostic value of admission versus $12 \mathrm{~h}$ hs-cTnT in a large cohort of 3,113 consecutive STEMI patients of one tertiary NHS hospital covering 1.6 million individuals in the northeast of England. Admission hs-cTnT was an independent predictor of short and long-term mortality while $12 \mathrm{~h}$ hs-cTnT was not. In support of this observation, increased admission hs-cTnT was linked with a higher risk profile in these patients compared to $12 \mathrm{~h}$ hs-cTnT. Specifically, admission hs-cTnT, but not $12 \mathrm{~h}$ hs-cTnT, was associated with (i) worse physiological status at presentation, including lower haemoglobin levels, higher heart rate, and increased incidence of cardiogenic shock; as well as (ii) parameters affecting the timing of 
revascularization, including more frequent inter-hospital transfer, longer door-to-balloon and symptom-onset-to-reperfusion time. This unfavourable profile at presentation, reflected by higher admission hs-cTnT levels, might explain the association of admission hs-cTnT with adverse procedural parameters, such as increased need for femoral access and higher incidence of coronary slow flow phenomenon.

The clinical prognostic utility of admission hs-cTnT was further confirmed by a substantial incremental predictive value over the best prognostic multivariable model for mortality in terms of calibration and reclassification. Importantly, our model incorporated confounders previously shown to be independently associated with mortality in patients with ACS and STEMI in large studies, such as age, diabetes mellitus, smoking, heart rate at presentation, creatinine levels, and TIMI flow post-reperfusion $(1,3,13)$. Taken together, these findings suggest that admission hs$\mathrm{cTnT}$ is a marker that may cumulatively inform about the duration of ischaemia, risk profile at presentation until the time of PPCI, adverse PPCI-related parameters, and the risk of mortality thereafter. In accordance with these results, three previous small studies suggested that admission cTn could predict 30-day, 9-month, and 1-year post-PPCI mortality in STEMI patients (11, 25)(26). Future studies should compare the prognostic performance between admission hs-cTnT and emerging biomarkers of cardiac ischaemia and reperfusion injury, such as microRNAs, in large cohorts (27).

In addition, our findings show that $12 \mathrm{~h}$ hs-cTnT may not provide clinically useful prognostic information in the era of PPCI. Currently, there is conflicting evidence regarding the short-term prognostic utility of post-procedural hs-cTn derived from relatively small STEMI populations lacking long-term follow-up (7-10). For example, in a recent study by Cediel et al. (7) peak levels of both contemporary cTnI and hs-cTnT assays did not predict MACE in 1,260 consecutive STEMI patients at 30 days and 1 year post-PPCI (7). In contrast, in a post-hoc analysis from a multicenter, phase II, randomized placebo-controlled trial (PROTECTION AMI trial) (10) post- 
PCI levels of cTnI were predictors of outcome in 1,066 patients. Accordingly, Ndrepepa G et al. showed that post-PPCI hs-cTnT was an independent predictor of 3-year all-cause mortality (26). Although not explicitly recommended by current international guidelines, post-PPCI hs-cTnT measurements are a common practice in some centres. Our findings suggest that post-PPCI hscTnT quantification is questionable, given that $12 \mathrm{~h}$ hs-cTnT does not seem to provide relevant prognostic information while it may bring additional economic burden to health systems.

In our study, while admission hs-cTnT showed consistently increasing hazard ratios with increasing concentrations, we observed a negative association between long-term mortality and low-medium concentrations of $12 \mathrm{~h}$ hs-cTnT. Considering that successful coronary reperfusion leads to a rapid washout of troponin within the initial $12 \mathrm{~h}(28)$, it may be hypothesized that this "protective" attribute of low to medium $12 \mathrm{~h}$ hs-cTnT concentrations could be a reflection of successful reperfusion whereas higher hs-cTnT levels at $12 \mathrm{~h}$ might reflect a slower release of troponin due to impaired reperfusion (29). Nano technology could be used in future trials to track troponin release in real time, thereby monitoring the reperfusion process as well as performing risk assessment right from hospital admission (30).

The present study has some limitations. Firstly, this was a retrospective, observational study. Therefore, there may have been relevant parameters that were not controlled for. For instance, echocardiographic data was only available for a minority of patients and hence not included in the prediction model. Secondly, $12 \mathrm{~h}$ hs-cTnT measurements were performed as part of routine clinical care, as per departmental standard operating protocol. Therefore, slight inter-patient variation in terms of blood collection timing at $12 \mathrm{~h}$ post-reperfusion could have occurred. Consequently, this study cannot entirely exclude the possibility that $12 \mathrm{~h}$ hs-cTnT could be a significant predictor of mortality with larger cohorts or strict sampling, in the context of a clinical trial. Thirdly, there was a small percentage of missing data for each variable included in the model. However, complete case analysis was the method used to deal with missing data and should not produce bias as the 


\section{Coelho-Lima et al.}

data was missing at random. Finally, generalisability of our findings should be taken with caution. In specific, hs-cTnT quartile thresholds were derived within-sample which poses a risk of model overfitting and requires validation in other cohorts.

In conclusion, this study provides evidence of an important and distinct role of admission hs-cTnT levels in predicting prognosis in STEMI patients undergoing PPCI as compared to $12 \mathrm{~h} \mathrm{hs}-\mathrm{cTnT}$. Our results strongly support the hypothesis that admission hs-cTnT levels combined with traditional outcome predictors could efficiently stratify patients with respect to their risk for mortality. Early and exact identification of STEMI patients at extreme mortality risk, facilitated by admission hs-cTnT measurements, may allow clinicians to properly diversify the escalation of medical care and precisely apply an intensified secondary prevention strategy. Finally, we demonstrate that $12 \mathrm{~h}$ hs-cTnT levels do not seem to be useful for prognostic stratification of STEMI patients.

Funding: JCL is supported by a PhD scholarship (Ministry of Education of Brazil) and an Academic development scholarship from Newcastle University. KStellos is supported by the European Research Council MODVASC grant. KSopova is supported by a scholarship from the German Heart Foundation (Deutsche Herzstiftung). IS is supported by the British Heart Foundation and Newcastle upon Tyne Hospitals NHS Charity. The sponsors had no role in the study design, data collection and analysis, writing of the manuscript or in the decision to submit the manuscript for publication.

Competing interests: none to declare.

Acknowledgements: Part of the research data shown in this manuscript was presented as a poster entitled "The additive value of pre-and post-reperfusion cardiac troponin T levels in risk 


\section{Coelho-Lima et al.}

Pre-reperfusion hs-cTnT predicts mortality in STEMI

stratification of patients with ST-segment elevation myocardial infarction" at the European Society of Cardiology (ESC) Congress 2019.

Contributorship statement: JCL and GG performed data analyses and interpretation and drafted the manuscript; JA, SERA, DG, FA, and AB performed data collection; CB, KS, LS, GR, and AB critically revised the manuscript for important intellectual content; K Stellos, K Stamatelopoulos, and IS provided substantial contributions to the conception and design of the work and critically revised the manuscript; KS and IS are responsible for the overall content of the work as guarantors. 


\section{REFERENCES}

1. Chung SC, Gedeborg R, Nicholas O, James S, Jeppsson A, Wolfe C, et al. Acute myocardial infarction: a comparison of short-term survival in national outcome registries in Sweden and the UK. Lancet. 2014;383(9925):1305-12.

2. Chung SC, Sundstrom J, Gale CP, James S, Deanfield J, Wallentin L, et al. Comparison of hospital variation in acute myocardial infarction care and outcome between Sweden and United Kingdom: population based cohort study using nationwide clinical registries. BMJ. 2015;351:h3913.

3. Pedersen F, Butrymovich V, Kelbaek H, Wachtell K, Helqvist S, Kastrup J, et al. Shortand long-term cause of death in patients treated with primary PCI for STEMI. J Am Coll Cardiol. 2014;64(20):2101-8.

4. Piepoli MF, Hoes AW, Agewall S, Albus C, Brotons C, Catapano AL, et al. 2016 European Guidelines on cardiovascular disease prevention in clinical practice: The Sixth Joint Task Force of the European Society of Cardiology and Other Societies on Cardiovascular Disease Prevention in Clinical Practice (constituted by representatives of 10 societies and by invited experts)Developed with the special contribution of the European Association for Cardiovascular Prevention \& Rehabilitation (EACPR). Eur Heart J. 2016;37(29):2315-81.

5. Thygesen K, Mair J, Giannitsis E, Mueller C, Lindahl B, Blankenberg S, et al. How to use high-sensitivity cardiac troponins in acute cardiac care. Eur Heart J. 2012;33(18):2252-7.

6. Thygesen K. What's new in the Fourth Universal Definition of Myocardial infarction? Eur Heart J. 2018;39(42):3757-8.

7. Cediel G, Rueda F, Garcia C, Oliveras T, Labata C, Serra J, et al. Prognostic Value of New-Generation Troponins in ST-Segment-Elevation Myocardial Infarction in the Modern Era: The RUTI-STEMI Study. Journal of the American Heart Association. 2017;6(12).

8. Boden H, Ahmed TA, Velders MA, van der Hoeven BL, Hoogslag GE, Bootsma M, et al. Peak and fixed-time high-sensitive troponin for prediction of infarct size, impaired left ventricular function, and adverse outcomes in patients with first ST-segment elevation myocardial infarction receiving percutaneous coronary intervention. The American journal of cardiology.

2013;111(10):1387-93.

9. Buber J, Laish-Farkash A, Koren-Morag N, Fefer P, Segev A, Hod H, et al. Cardiac troponin elevation pattern in patients undergoing a primary percutaneous coronary intervention for ST-segment elevation myocardial infarction: characterization and relationship with cardiovascular events during hospitalization. Coronary artery disease. 2015;26(6):503-9.

10. Hall TS, Hallen J, Krucoff MW, Roe MT, Brennan DM, Agewall S, et al. Cardiac troponin I for prediction of clinical outcomes and cardiac function through 3-month follow-up after primary percutaneous coronary intervention for ST-segment elevation myocardial infarction. American heart journal. 2015;169(2):257-65.e1.

11. Wang TK, Snow TA, Chen Y, Rostom H, White JM, Stewart JT, et al. High-sensitivity troponin level pre-catheterization predicts adverse cardiovascular outcomes after primary 
angioplasty for ST-elevation myocardial infarction. European heart journal Acute cardiovascular care. 2014;3(2):118-25.

12. Task Force on the management of STseamiotESoC, Steg PG, James SK, Atar D, Badano LP, Blomstrom-Lundqvist C, et al. ESC Guidelines for the management of acute myocardial infarction in patients presenting with ST-segment elevation. Eur Heart J. 2012;33(20):2569-619.

13. Fox KA, Fitzgerald G, Puymirat E, Huang W, Carruthers K, Simon T, et al. Should patients with acute coronary disease be stratified for management according to their risk?

Derivation, external validation and outcomes using the updated GRACE risk score. BMJ Open. 2014;4(2):e004425.

14. Stamatelopoulos K, Mueller-Hennessen M, Georgiopoulos G, Sachse M, Boeddinghaus J, Sopova K, et al. Amyloid-beta (1-40) and Mortality in Patients With Non-ST-Segment Elevation Acute Coronary Syndrome: A Cohort Study. Ann Intern Med. 2018;168(12):855-65.

15. Pencina MJ, D'Agostino RB, Sr., Steyerberg EW. Extensions of net reclassification improvement calculations to measure usefulness of new biomarkers. Stat Med. 2011;30(1):11-21.

16. Ridker PM, Everett BM, Thuren T, MacFadyen JG, Chang WH, Ballantyne C, et al. Antiinflammatory Therapy with Canakinumab for Atherosclerotic Disease. N Engl J Med. 2017;377(12):1119-31.

17. Schwartz GG, Steg PG, Szarek M, Bhatt DL, Bittner VA, Diaz R, et al. Alirocumab and Cardiovascular Outcomes after Acute Coronary Syndrome. The New England journal of medicine. 2018.

18. Sabatine MS, Giugliano RP, Keech AC, Honarpour N, Wiviott SD, Murphy SA, et al. Evolocumab and Clinical Outcomes in Patients with Cardiovascular Disease. N Engl J Med. 2017;376(18):1713-22.

19. Zelniker TA, Wiviott SD, Raz I, Im K, Goodrich EL, Bonaca MP, et al. SGLT2 inhibitors for primary and secondary prevention of cardiovascular and renal outcomes in type 2 diabetes: a systematic review and meta-analysis of cardiovascular outcome trials. Lancet. 2018.

20. Bohula EA, Morrow DA, Giugliano RP, Blazing MA, He P, Park JG, et al. Atherothrombotic Risk Stratification and Ezetimibe for Secondary Prevention. J Am Coll Cardiol. 2017;69(8):911-21.

21. Halkin A, Singh M, Nikolsky E, Grines CL, Tcheng JE, Garcia E, et al. Prediction of mortality after primary percutaneous coronary intervention for acute myocardial infarction: the CADILLAC risk score. J Am Coll Cardiol. 2005;45(9):1397-405.

22. Wu C, Hannan EL, Walford G, Ambrose JA, Holmes DR, Jr., King SB, 3rd, et al. A risk score to predict in-hospital mortality for percutaneous coronary interventions. J Am Coll Cardiol. 2006;47(3):654-60.

23. de Mulder M, Gitt A, van Domburg R, Hochadel M, Seabra-Gomes R, Serruys PW, et al. EuroHeart score for the evaluation of in-hospital mortality in patients undergoing percutaneous coronary intervention. Eur Heart J. 2011;32(11):1398-408. 
24. Bawamia B, Mehran R, Qiu W, Kunadian V. Risk scores in acute coronary syndrome and percutaneous coronary intervention: a review. Am Heart J. 2013;165(4):441-50.

25. Giannitsis E, Muller-Bardorff M, Lehrke S, Wiegand U, Tolg R, Weidtmann B, et al. Admission troponin T level predicts clinical outcomes, TIMI flow, and myocardial tissue perfusion after primary percutaneous intervention for acute ST-segment elevation myocardial infarction. Circulation. 2001;104(6):630-5.

26. Ndrepepa G, Kufner S, Hoyos M, Harada Y, Xhepa E, Hieber J, et al. High-sensitivity cardiac troponin $\mathrm{T}$ and prognosis in patients with ST-segment elevation myocardial infarction. $\mathrm{J}$ Cardiol. 2018;72(3):220-6.

27. Coelho-Lima J, Mohammed A, Cormack S, Jones S, Ali A, Panahi P, et al. Kinetics Analysis of Circulating MicroRNAs Unveils Markers of Failed Myocardial Reperfusion. Clin Chem. 2020;66(1):247-56.

28. Katus HA, Remppis A, Scheffold T, Diederich KW, Kuebler W. Intracellular compartmentation of cardiac troponin $\mathrm{T}$ and its release kinetics in patients with reperfused and nonreperfused myocardial infarction. The American journal of cardiology. 1991;67(16):1360-7.

29. Reffelmann T, Kloner RA. The "no-reflow" phenomenon: basic science and clinical correlates. Heart (British Cardiac Society). 2002;87(2):162-8.

30. McClements J, Seumo Tchekwagep PM, Vilela Strapazon AL, Canfarotta F, Thomson A, Czulak J, et al. Immobilization of Molecularly Imprinted Polymer Nanoparticles onto Surfaces Using Different Strategies: Evaluating the Influence of the Functionalized Interface on the Performance of a Thermal Assay for the Detection of the Cardiac Biomarker Troponin I. ACS Appl Mater Interfaces. 2021. 


\section{Coelho-Lima et al.}

Pre-reperfusion hs-cTnT predicts mortality in STEMI

Table 1. Baseline characteristics of the study cohort.

\begin{tabular}{|c|c|c|c|c|}
\hline Variable & Entire cohort & Survivors & Non-survivors & $p$ value \\
\hline Sample size, n (\%) & $3,113(100)$ & $2604(83.6)$ & $509(16.4)$ & \\
\hline Gender (female), n (\%) & $2,211(71)$ & $706(27.1)$ & $196(38.5)$ & $<0.001$ * \\
\hline Age [years, mean (SD)] & $62.9(12.7)$ & $60.7(11.9)$ & $73.9(11.1)$ & $<0.001$ \# \\
\hline \multicolumn{5}{|l|}{ Risk factors, n (\%) } \\
\hline \multicolumn{5}{|l|}{ Smoking status } \\
\hline Never smoked & $781(26.7)$ & $669(26.8)$ & $112(25.8)$ & $0.661^{*}$ \\
\hline Ex-smoker & $813(27.8)$ & $638(25.6)$ & $175(40.3)$ & $<0.001$ * \\
\hline Current smoker & $1,335(45.6)$ & $1,188(47.6)$ & $147(33.9)$ & $<\mathbf{0 . 0 0 1}^{*}$ \\
\hline Family history of CAD & $1,361(46.1)$ & $1,232(49)$ & $129(29.5)$ & $<0.001^{*}$ \\
\hline Hypertension & $1,434(46.1)$ & $1,132(43.5)$ & $302(59.3)$ & $<0.001 *$ \\
\hline Diabetes Mellitus & $393(12.8)$ & $291(11.3)$ & $102(20.6)$ & $<0.001 *$ \\
\hline Hypercholesterolemia & $1,216(39.1)$ & $1,017(39.1)$ & $199(39.1)$ & $0.986^{*}$ \\
\hline Obesity & 807 (28.2) & $723(29.5)$ & $84(20.1)$ & $<0.001 *$ \\
\hline \multicolumn{5}{|l|}{ Medical history of CAD, n (\%) } \\
\hline Previous angina & $529(17.1)$ & $403(15.5)$ & $126(25.6)$ & $<0.001 *$ \\
\hline Previous MI & $321(10.4)$ & $218(8.4)$ & $103(21.1)$ & $<0.001 *$ \\
\hline Previous PCI & $201(6.5)$ & $157(6)$ & $44(8.7)$ & $0.025^{*}$ \\
\hline Previous CABG & $56(1.8)$ & $41(1.6)$ & $15(3)$ & $\mathbf{0 . 0 3 3} 3^{\S}$ \\
\hline \multicolumn{5}{|l|}{ Clinical characteristics on admission } \\
\hline Heart rate, bpm [median (IQR)] & $75(63-88)$ & $74(62-87)$ & $80(65-95)$ & $<0.001$ \& \\
\hline Systolic BP, mmHg [median (IQR)] & $127(109-147)$ & $127(110-147)$ & $123(100-145)$ & $0.001^{\S}$ \\
\hline Cardiogenic shock, n (\%) & $128(4.1)$ & $69(2.7)$ & $59(11.7)$ & $<0.001 *$ \\
\hline \multicolumn{5}{|l|}{ Admission route, $\mathrm{n}(\%)$} \\
\hline Emergency services & $2,264(72.3)$ & $1,898(72.9)$ & $366(71.9)$ & $0.649^{*}$ \\
\hline Inter-hospital transfer & $849(27.3)$ & $706(27.1)$ & $143(28.1)$ & $0.649^{*}$ \\
\hline Door to balloon, min [median (IQR)] & $23(18-33)$ & $23(17-32)$ & $26(19-38)$ & $<0.001$ \& \\
\hline $\begin{array}{l}\text { Onset to reperfusion, min } \\
\text { [median (IQR)] }\end{array}$ & $132(104-187)$ & $164(115-261)$ & $193(131-313)$ & $<0.001$ § \\
\hline \multicolumn{5}{|l|}{ Infarct location, $\mathrm{n}(\%)$} \\
\hline Anterior & $1,207(39.3)$ & $979(37.9)$ & $228(46.2)$ & $0.001^{*}$ \\
\hline \multicolumn{5}{|l|}{ Biochemical tests [median (IQR)] } \\
\hline Admission haemoglobin, g/dL & $\begin{array}{c}13.8 \\
(12.6-14.9)\end{array}$ & $\begin{array}{c}14 \\
(12.8-15)\end{array}$ & $\begin{array}{c}12.7 \\
(11.3-14)\end{array}$ & $<0.001^{\text {\& }}$ \\
\hline Admission creatinine, $\mu \mathrm{mol} / \mathrm{L}$ & $81(69-96)$ & $79(68-93)$ & $91(75-119)$ & $<0.001$ § \\
\hline Admission hs-cTnT, ng/L & $\begin{array}{c}121 \\
(39-515)\end{array}$ & $\begin{array}{c}104 \\
(35-429)\end{array}$ & $\begin{array}{c}229 \\
(68-974)\end{array}$ & $<0.001^{\text {\& }}$ \\
\hline 12h hs-cTnT, ng/L & $\begin{array}{c}2,200 \\
(775-5,223)\end{array}$ & $\begin{array}{c}2,170 \\
(767-5,063)\end{array}$ & $\begin{array}{c}2,319 \\
(815-6,543)\end{array}$ & $0.053^{\S}$ \\
\hline Arterial access, n (\%) & & & & \\
\hline
\end{tabular}




\begin{tabular}{lcccc}
\hline Radial & $2,640(85.1)$ & $2270(87.2)$ & $370(72.8)$ & $<\mathbf{0 . 0 0 1}^{*}$ \\
Femoral & $464(14.9)$ & $329(12.6)$ & $135(26.6)$ & $<\mathbf{0 . 0 0 1}^{*}$ \\
Brachial & $6(0.2)$ & $3(50)$ & $3(50)$ & $0.093^{*}$ \\
GPIIb/IIIa medication, n (\%) & $2,016(65.2)$ & $1750(67.7)$ & $266(52.6)$ & $<\mathbf{0 . 0 0 1}^{*}$ \\
Contrast volume, mL [median (IQR)] & $140(110-180)$ & $140(110-175)$ & $150(110-180)$ & $0.5900^{\S}$ \\
TIMI flow pre-PCI, n (\%) & & & & \\
$\mathbf{1}$ & $136(4.5)$ & $108(4.3)$ & $28(5.7)$ & $0.178^{*}$ \\
$\mathbf{2}$ & $275(9.2)$ & $227(9)$ & $48(9.7)$ & $0.622^{*}$ \\
$\mathbf{3}$ & $384(12.8)$ & $316(12.6)$ & $68(13.8)$ & $0.461^{*}$ \\
Thrombectomy & $1,866(60.2)$ & $1592(61.4)$ & $274(53.9)$ & $\mathbf{0 . 0 0 2}^{*}$ \\
Number of stents & & & & \\
$\mathbf{0}$ & $174(5.6)$ & $107(4.1)$ & $67(13.2)$ & $<\mathbf{0 . 0 0 1}^{*}$ \\
$\mathbf{1}$ & $1,707(54.8)$ & $1454(55.8)$ & $253(49.7)$ & $\mathbf{0 . 0 1 1}^{*}$ \\
$\mathbf{2}$ & $870(27.9)$ & $738(28.3)$ & $132(25.9)$ & $0.268^{*}$ \\
$\mathbf{3}$ & $266(8.5)$ & $219(8.4)$ & $47(9.2)$ & $0.543^{*}$ \\
Intra-procedural complications & & & & $<$ \\
Coronary slow flow & $59(1.9)$ & $35(1.3)$ & $24(4.7)$ & $<\mathbf{0 . 0 0 1}^{*}$ \\
Coronary dissection & $37(1.2)$ & $32(1.2)$ & $5(1)$ & $0.639^{*}$ \\
Direct current cardioversion & $26(0.8)$ & $15(0.6)$ & $11(2.2)$ & $<\mathbf{0 . 0 0 1}^{*}$ \\
TIMI flow post-PCI, n (\%) & & & & $<$ \\
$\mathbf{0}$ & $72(2.4)$ & $42(1.7)$ & $30(6.2)$ & $<\mathbf{0 . 0 0 1}^{*}$ \\
$\mathbf{1}$ & $30(1)$ & $19(0.8)$ & $11(2.3)$ & $\mathbf{0 . 0 0 2}^{*}$ \\
$\mathbf{2}$ & $123(4.1)$ & $82(3.3)$ & $41(8.4)$ & $<\mathbf{0 . 0 0 1}^{*}$ \\
$\mathbf{3}$ & $2,776(92.5)$ & $2372(94.3)$ & $404(83.1)$ & $<\mathbf{0 . 0 0 1}^{*}$ \\
\hline
\end{tabular}

Comparisons in the distribution of variables between survivors and non-survivors were performed using ttest (\#) or Mann-Whitney U (§) and chi-square test (*) for continuous and categorical variables, respectively.

Abbreviations: $\mathrm{BP}$, blood pressure; $\mathrm{CABG}$, coronary artery bypass graft; $\mathrm{CAD}$, coronary artery disease; cTnT, cardiac troponin T; GP IIb/IIIa, glycoprotein IIb/IIIa; hs-cTnT, high sensitivity cardiac troponin T; IQR, interquartile range; MI, myocardial infarction; PCI, percutaneous coronary intervention; TIMI, thrombolysis in myocardial infarction angiographic score. 
Table 2. Association of admission and $12 \mathrm{~h}$ hs-cTnT with the study endpoints by univariable and multivariable Cox regression

\begin{tabular}{|c|c|c|c|c|}
\hline & \multicolumn{4}{|c|}{ Study endpoints } \\
\hline & \multicolumn{2}{|c|}{ In-hospital mortality } & \multicolumn{2}{|c|}{ Overall mortality } \\
\hline & HR* $(95 \% \mathrm{CI})$ & p-value & $\begin{array}{c}\mathrm{HR}^{*}(95 \% \\
\mathrm{CI})\end{array}$ & p value \\
\hline $\begin{array}{l}\text { Admission hs-cTnT } \\
\text { (unadjusted) }\end{array}$ & $4.26(2.80-6.47)$ & $<0.001$ & $\begin{array}{c}1.83(1.53- \\
2.19)\end{array}$ & $<0.001$ \\
\hline $\begin{array}{l}\text { Admission hs-cTnT } \\
\text { (Core model) }\end{array}$ & $2.53(1.32-4.85)$ & 0.005 & $\begin{array}{c}1.27(1.02- \\
1.59)\end{array}$ & 0.029 \\
\hline & $\mathrm{HR} \dagger(95 \% \mathrm{CI})$ & p-value & $\mathrm{HR} \dagger(95 \% \mathrm{CI})$ & p value \\
\hline $\begin{array}{l}\text { 12h hs-cTnT } \\
\text { (unadjusted) }\end{array}$ & $1.10(0.69-1.73)$ & 0.679 & $\begin{array}{c}1.40(1.16- \\
1.69)\end{array}$ & $<0.001$ \\
\hline $\begin{array}{l}12 \mathrm{~h} \text { hs-cTnT } \\
\text { (Core model) }\end{array}$ & $1.35(0.69-2.65)$ & 0.373 & $\begin{array}{c}1.15(0.92- \\
1.44)\end{array}$ & 0.214 \\
\hline
\end{tabular}

*HR corresponds to admission hs-cTnT levels $>515 \mathrm{ng} / \mathrm{L}$ ( $4^{\text {th }}$ quartile versus the lower quartiles). $\dagger$ HR corresponds to $12 \mathrm{~h}$ hs-cTnT levels $>5,221 \mathrm{ng} / \mathrm{L}$ ( $4^{\text {th }}$ quartile versus the lower quartiles).

Core model for mortality prediction: age (per decade), current smoking, diabetes mellitus, previous myocardial infarction, pre-PPCI haemoglobin, pre-PPCI creatinine (per $100 \mathrm{mmoL}$ ), heart rate on admission, anterior myocardial infarction, administration of glycoprotein IIb/IIIa inhibitors, TIMI score 3 post-PPCI, door-to-balloon time.

Abbreviations: CI, confidence interval; GPIIb/IIIa, glycoprotein IIb/IIIa; HR, hazard ratio; hs-cTnT, high sensitivity cardiac troponin T; SE, standard error; PPCI, primary percutaneous coronary intervention; TIMI, thrombolysis in myocardial infarction score. 
Table 3. Additive predictive value of admission hs-cTnT over the core model for in-hospital and overall all-cause mortality

\begin{tabular}{|c|c|c|c|c|c|c|}
\hline & \multicolumn{2}{|c|}{ Calibration } & \multicolumn{4}{|c|}{ Reclassification } \\
\hline & $\begin{array}{l}\text { LR test chi- } \\
\text { squared }\end{array}$ & P-value & Events & Non events & $\begin{array}{l}\text { Overall NRI } \\
(95 \% \mathrm{CI})^{* *}\end{array}$ & P-value \\
\hline $\begin{array}{c}\text { *In-hospital } \\
\text { death }\end{array}$ & 15.47 & $<0.001$ & $-11.8 \%$ & $+70.5 \%$ & $\begin{array}{c}+0.588 \\
(0.278, \\
0.903)\end{array}$ & $<0.001$ \\
\hline $\begin{array}{c}\text { * Overall all- } \\
\text { cause } \\
\text { mortality }\end{array}$ & 11.73 & 0.001 & $-39.8 \%$ & $+57.6 \%$ & $\begin{array}{l}+0.178 \\
(0.037, \\
0.311)\end{array}$ & 0.001 \\
\hline
\end{tabular}

*High-sensitivity cTnT was added on the core model including age, pre-PCI haemoglobin, pre-PCI creatinine, heart rate on admission, cardiogenic shock on admission, femoral access, anterior myocardial infarction, TIMI flow 3 post-PPCI

** 95\% bias-corrected CIs were derived from bootstrapping with 1,000 replicates

LR depicts goodness of fit of predicted against observed values (calibration)

Events and non-events depict percentage of patients reclassified to higher or lower risk in patients with or without the event, respectively

$(-)$ depicts incorrect reclassification and $(+)$ depicts correct reclassification of risk within the events or non-events groups

Overall NRI depicts a unitless measure of reclassification (range 0-2)

Abbreviations: LR: likelihood ratio, NRI: net reclassification index, PPCI: percutaneous coronary intervention, TIMI: Thrombolysis in Myocardial Infarction 


\section{Figure legends}

\section{Figure 1. Admission and $12 \mathrm{~h}$ post-PPCI hs-cTn levels, and mortality in STEMI patients.} Kaplan-Meier survival curves depicting the association of admission hs-cTnT quartiles with probability of in-hospital (A) and overall (B) mortality in STEMI patients. Kaplan-Meier survival curves displaying the association between $12 \mathrm{~h}$ post-PCI hs-cTnT quartiles and in-hospital (C) as well as overall mortality (D).

Figure 2. Dose-response relationship between continuous hs-cTnT and mortality. Smoothed restricted cubic spline (RCS) plots of the log hazard ratio (HR) for in-hospital (A, B) and overall mortality (C, D) versus levels of admission hs-cTnT (A, C) and post-PCI hs-cTnT (B, D). Three knots were fixed at the $10^{\text {th }}\left(16\right.$ and $257.1 \mathrm{ng} / \mathrm{L}$ for admission and $12 \mathrm{~h} \mathrm{cTnT}$, respectively), $50^{\text {th }}$ (121 and 2,200ng/L for admission and $12 \mathrm{~h} \mathrm{cTnT}$, respectively) and $90^{\text {th }}(1,557$ and $9,547 \mathrm{ng} / \mathrm{L}$ for admission and $12 \mathrm{~h}$ cTnT, respectively) percentile of cTnT distribution. The upper- and lowermost dotted curves represent the 95\% CI about the predicted HRs (middle solid line). Vertical dashed lines indicate the location of the $20^{\text {th }}$ and $80^{\text {th }}$ percentile of continuous hs-cTnT distribution which are further compared (difference in log hazard ratio for the $80^{\text {th }}$ percentile of hs-cTnT versus the $20^{\text {th }}$ percentile as the reference value) after controlling for age, current smoking, diabetes mellitus, previous myocardial infarction, pre-PPCI haemoglobin, pre-PPCI creatinine, heart rate on admission, anterior myocardial infarction, administration of glycoprotein IIb/IIIa

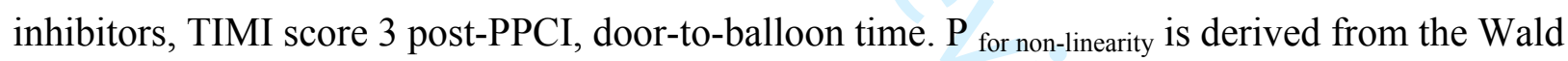
test for the non-linear term of the RCS; $\mathrm{P}_{\text {overall }}$ stems from the joint Wald test for the linear and non-linear term of RCS To enhance clarity of graphics, values exceeding the 90th percentile of hs-cTnT distribution were censored in corresponding plots. A horizontal dotted line (grey color) has been placed at 0 value of $\mathrm{Y}$ axis to indicate absence of association with the outcome. CI, confidence intervals; hs-cTnT, high-sensitivity cardiac troponin T; PPCI, primary percutaneous coronary intervention. 


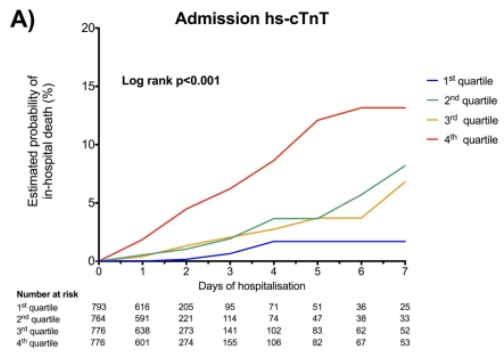

B) ${ }^{30} \quad$ Admission hs-cTnT

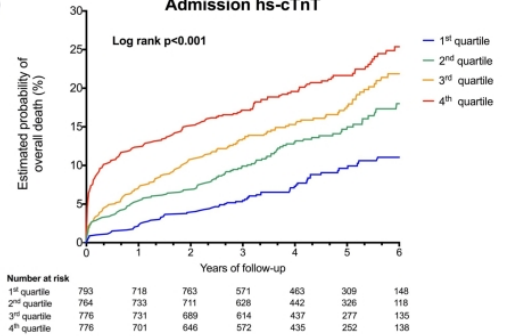

C)

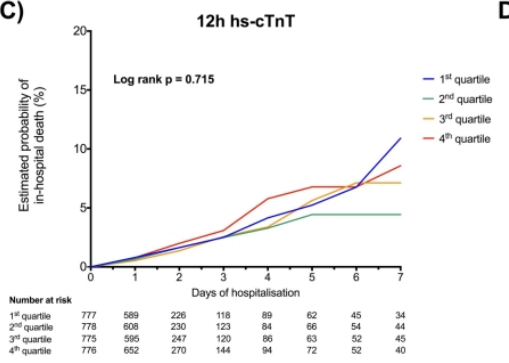

D)

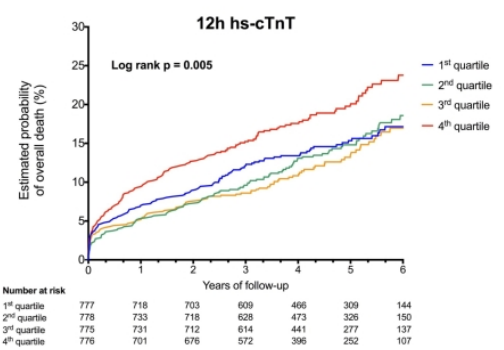

Figure 1

$338 \times 190 \mathrm{~mm}(300 \times 300$ DPI $)$ 

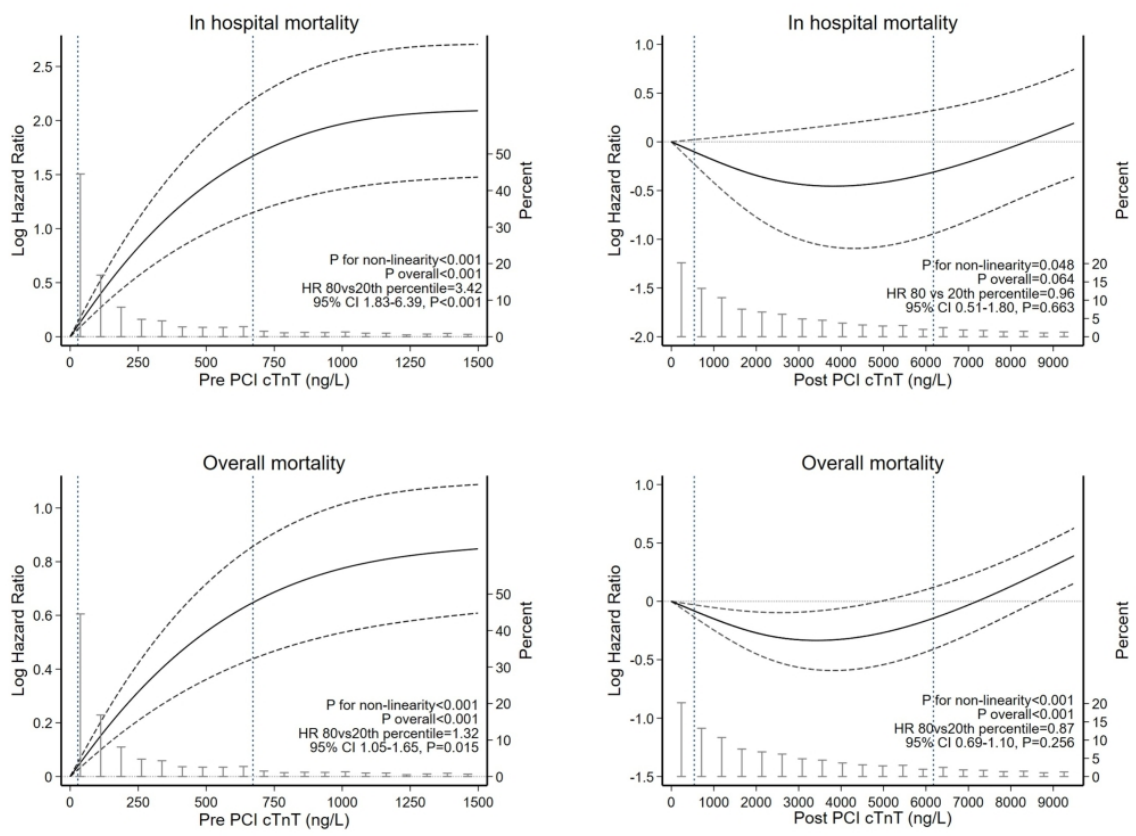

Figure 2

$253 \times 190 \mathrm{~mm}(300 \times 300 \mathrm{DPI})$

https://mc.manuscriptcentral.com/heart 


\section{Supplements}




\section{Supplemental methods}

\section{Proportional-hazards regression and dose-response curves}

The proportional hazards assumption in Cox regression analyses was evaluated graphically and statistically by using the Schoenfeld residuals. Selection of optimal number of knots for restricted cubic splines (RCS) was based on log likelihood ratio tests. Knots for RCS were fixed at the 10th, 50th and 90th percentile of the hs-cTnT distribution. The smoothed plots of log hazard ratio (HR) for each outcome versus the continuous hs-cTnT (dose-response curves) were controlled for the covariates that comprised the corresponding core model. Non-linear and the overall associations of the transformed hs-cTnT (i.e., RCS) with logHR were assessed by examining the statistical significance (Wald test) of the non-linear or both (linear and non-linear) terms (1). We also compared the $80^{\text {th }}$ against the $20^{\text {th }}$ percentile of the hs-cTnT values distribution to derive statistical inference on the association between circulating levels of this biomarker and the outcomes of the study after controlling for the core model. 
Coelho-Lima et al. Pre-reperfusion hs-cTnT predicts mortality in STEMI

\section{Supplemental tables}

Supplemental table 1. Establishing a core model of mortality prediction in STEMI.

\begin{tabular}{|c|c|c|}
\hline \multirow[t]{2}{*}{ Variable } & \multicolumn{2}{|c|}{ Multivariable Cox-regression } \\
\hline & HR $(95 \% \mathrm{Cl})$ & $p$ value \\
\hline Age (per decade) & $2.41(2.12-2.74)$ & $<0.001$ \\
\hline Gender (female) & $0.77(0.61-1.00)$ & 0.052 \\
\hline Current smoking & $1.85(1.42-2.42)$ & $<0.001$ \\
\hline Family history of CAD & $0.81(0.63-1.04)$ & 0.111 \\
\hline Hypertension & $1.21(0.94-1.54)$ & 0.130 \\
\hline Diabetes Mellitus & $1.48(1.11-1.98)$ & 0.007 \\
\hline Obesity & $0.92(0.67-1.25)$ & 0.692 \\
\hline Hypercholesterolaemia & $0.91(0.73-1.18)$ & 0.505 \\
\hline Previous angina & $0.97(0.71-1.33)$ & 0.875 \\
\hline Previous MI & $1.62(1.22-2.16)$ & 0.001 \\
\hline Previous PCl & $0.97(0.59-1.61)$ & 0.928 \\
\hline Previous CABG & $0.74(0.37-1.48)$ & 0.402 \\
\hline Admission haemoglobin & $0.89(0.83-0.95)$ & 0.001 \\
\hline Admission creatinine & $1.26(1.09-1.45)$ & 0.001 \\
\hline \multicolumn{3}{|l|}{ (per 100mmol) } \\
\hline Heart rate (per 10 beats) & $1.07(1.02-1.13)$ & 0.004 \\
\hline Cardiogenic shock & $1.22(0.67-2.21)$ & 0.505 \\
\hline Inter-hospital transfer & $0.83(0.63-1.10)$ & 0.203 \\
\hline Onset to reperfusion (min) & $1.00(1.00-1.00)$ & 0.848 \\
\hline Door to balloon ( $\mathrm{min}$ ) & $1.00(1.00-1.00)$ & $<0.001$ \\
\hline Anterior MI & $1.38(1.10-1.74)$ & 0.005 \\
\hline Femoral access & $1.23(0.91-1.66)$ & 0.160 \\
\hline GPIIb/IIla inhibitors & $0.78(0.61-0.98)$ & 0.036 \\
\hline Contrast volume (ml) & $1.00(1.00-1.00)$ & 0.109 \\
\hline TIMI 3 flow pre-PCI & $0.86(0.59-1.24)$ & 0.428 \\
\hline Thrombectomy & $1.17(0.92-1.49)$ & 0.178 \\
\hline Coronary slow flow & $1.32(0.70-2.51)$ & 0.384 \\
\hline TIMI 3 flow post-PCI & $0.48(0.35-0.65)$ & $<0.001$ \\
\hline
\end{tabular}

Abbreviations: CAD, coronary artery disease; CI, confidence interval; GPIIb/IIIa, glycoprotein IIb/IIIa; HR, hazard ratio; MI, myocardial infarction; PCI, percutaneous coronary intervention; TIMI, thrombolysis in myocardial infarction angiographic score. 
Coelho-Lima et al.

Pre-reperfusion hs-cTnT predicts mortality in STEMI

Supplemental table 2. Percentage of missing data for variables included in the core prediction models of in-hospital and longer-term mortality

\begin{tabular}{|c|c|c|}
\hline \multirow{2}{*}{ Variable } & \multicolumn{2}{|c|}{ Missing cases } \\
\hline & $n$ & $\%$ \\
\hline Age & 0 & 0 \\
\hline Current smoking & 184 & 5.9 \\
\hline Diabetes & 31 & 1 \\
\hline Previous MI & 27 & 0.9 \\
\hline $\begin{array}{l}\text { Pre-PCI } \\
\text { haemoglobin }\end{array}$ & 38 & 1.22 \\
\hline Pre-PCl creatinin & 35 & 1.12 \\
\hline $\begin{array}{l}\text { Heart rate at } \\
\text { admission }\end{array}$ & 63 & 2.02 \\
\hline Cardiogenic shor & 18 & 0.6 \\
\hline Anterior MI & 39 & 1.3 \\
\hline Femoral access & 3 & 0.1 \\
\hline Contrast volume & 54 & 1.73 \\
\hline $\begin{array}{l}\text { GP Ilb/IIla } \\
\text { medication }\end{array}$ & 21 & 0.7 \\
\hline $\begin{array}{l}\text { TIMI flow } 3 \text { post } \\
\text { PCI }\end{array}$ & 112 & 3.6 \\
\hline
\end{tabular}

Abbreviations: GPIIb/IIIa, glycoprotein IIb/IIIa; MI, myocardial infarction; PCI, percutaneous coronary intervention; TIMI, thrombolysis in myocardial infarction angiographic score. 
Supplemental table 3. Baseline clinical characteristics of the study population according to admission hs-cTnT quartiles

\begin{tabular}{|c|c|c|c|c|c|c|}
\hline Variable & Entire cohort & $\begin{array}{c}1^{\text {st }} \text { quartile of } \\
\text { admission } \\
\text { hs-cTnT } \\
\text { (<39 ng/L) }\end{array}$ & $\begin{array}{l}2^{\text {nd }} \text { quartile of } \\
\text { admission } \\
\text { hs-cTnT } \\
\text { (39-121ng/L) }\end{array}$ & $\begin{array}{c}3^{\text {rd }} \text { quartile of } \\
\text { admission } \\
\text { hs-cTnT } \\
\text { (122- } 515 \mathrm{ng} / \mathrm{L})\end{array}$ & $\begin{array}{c}4^{\text {th }} \text { quartile of } \\
\text { admission } \\
\text { hs-cTnT } \\
\text { (> } 515 \mathrm{ng} / \mathrm{L} \text { ) }\end{array}$ & $p$ value \\
\hline Sample size, n (\%) & $3,113(100)$ & $794(25.5)$ & $765(24.6)$ & $777(25)$ & $777(25)$ & \\
\hline Gender (male), n (\%) & $2,211(71)$ & $575(72.4)$ & $551(72)$ & $536(69)$ & 549 (70.7) & 0.432 \\
\hline Age [years, mean (SD)] & $62.9(12.7)$ & $59.9(11.5)$ & $62.8(12.7)$ & $64.9(12.7)$ & $64.1(13.3)$ & $<0.001$ \\
\hline \multicolumn{7}{|l|}{ Risk factors, n (\%) } \\
\hline \multicolumn{7}{|l|}{ Smoking status } \\
\hline Never smoked & $781(26.7)$ & $179(23.5)$ & $193(26.7)$ & $214(29.3)$ & $195(27.3)$ & 0.088 \\
\hline Ex-smoker & $813(27.8)$ & $186(24.4)$ & $230(31.8)$ & $195(26.7)$ & $202(28.3)$ & 0.014 \\
\hline Current smoker & $1,335(45.6)$ & $396(52)$ & $300(41.5)$ & $322(44)$ & $317(44.4)$ & $<0.001$ \\
\hline Family history of CAD & $1,361(46.1)$ & $386(50.2)$ & 337 (46.2) & $345(46.4)$ & $293(41.2)$ & 0.007 \\
\hline Hypertension & $1,434(46.1)$ & $360(45.3)$ & $355(46.4)$ & $374(48.1)$ & $345(44.4)$ & 0.492 \\
\hline Diabetes Mellitus & $393(12.8)$ & $98(12.5)$ & $98(13)$ & $89(11.5)$ & $108(14.1)$ & 0.514 \\
\hline Hypercholesterolemia & $1,216(39.1)$ & $329(41.4)$ & $303(39.6)$ & $290(37.3)$ & $294(37.8)$ & 0.327 \\
\hline Obesity & $807(28.2)$ & $235(31.2)$ & $209(29.1)$ & 169 (23.9) & $194(28.3)$ & 0.019 \\
\hline \multicolumn{7}{|c|}{ Medical history of CAD, $n(\%)$} \\
\hline Previous angina & $529(17.1)$ & $144(18.2)$ & $148(19.4)$ & $122(15.8)$ & $115(15)$ & 0.073 \\
\hline Previous MI & $321(10.4)$ & $84(10.6)$ & $87(11.4)$ & $80(10.4)$ & $70(9.2)$ & 0.538 \\
\hline Previous $\mathrm{PCl}$ & $201(6.5)$ & $65(8.2)$ & $52(6.8)$ & $42(5.4)$ & $42(5.4)$ & 0.077 \\
\hline Previous CABG & $56(1.8)$ & $16(2)$ & $13(1.7)$ & $15(1.9)$ & $12(1.5)$ & 0.895 \\
\hline Clinical characteristics on & & & & & & \\
\hline
\end{tabular}


Pre-reperfusion hs-cTnT predicts mortality in STEMI

\begin{tabular}{|c|c|c|c|c|c|c|}
\hline Heart rate, bpm [median (IQR)] & $75(63-88)$ & $70(60-82)$ & $75(63-88)$ & $76(64-88)$ & $80(68-95)$ & $<0.001$ \\
\hline Systolic BP, mmHg [median (IQR)] & $127(109-147)$ & $126(110-147)$ & $126(110-144)$ & $128(110-149)$ & $126(107-147)$ & 0.848 \\
\hline Cardiogenic shock, n (\%) & $128(4.1)$ & $14(1.8)$ & $24(3.2)$ & $34(4.4)$ & $56(7.3)$ & $<0.001$ \\
\hline \multicolumn{7}{|l|}{ Admission route, $\mathrm{n}(\%)$} \\
\hline Emergency services & $2,264(72.3)$ & $670(84.4)$ & $563(73.6)$ & $524(67.4)$ & $507(65.3)$ & $<0.001$ \\
\hline Inter-hospital transfer & $849(27.3)$ & $124(15.6)$ & $202(26.4)$ & $253(32.6)$ & $270(34.7)$ & $<0.001$ \\
\hline Door to balloon, min [median (IQR)] & $23(18-33)$ & $23(18-31)$ & $23(17-34)$ & $23(18-32)$ & $24(18-36)$ & 0.008 \\
\hline Onset to reperfusion, $\min$ & $132(104-187)$ & $132(104-187)$ & $164(117-241)$ & $190(127-289)$ & $219(134-445)$ & $<0.001$ \\
\hline \multicolumn{7}{|l|}{ [median (IQR)] } \\
\hline \multicolumn{7}{|l|}{ Infarct location, $\mathbf{n}(\%)$} \\
\hline Anterior & $1,207(39.3)$ & $223(28.4)$ & $292(38.5)$ & $315(41)$ & $377(49.3)$ & $<0.001$ \\
\hline \multicolumn{7}{|l|}{ Biochemical tests [median (IQR)] } \\
\hline Admission haemoglobin, g/dL & 13.8 & 14.2 & 13.9 & 13.6 & 13.5 & $<0.001$ \\
\hline & $(12.6-14.9)$ & $(13-15.2)$ & $(12.7-15)$ & $(12.3-14.7)$ & $(12.3-14.7)$ & \\
\hline Admission creatinine, $\mu \mathrm{mol} / \mathrm{L}$ & $81(69-96)$ & $80(69-93)$ & $82(70-96)$ & $80(67-95)$ & $81(69-99)$ & 0.019 \\
\hline Admission hs-cTnT, ng/L & 121 & 19 & 69 & 227 & 1,239 & $<0.001$ \\
\hline & $(39-515)$ & $(12-28)$ & $(54-89)$ & $(160-340)$ & $(740-2,373)$ & 20.001 \\
\hline 12h hs-cTnT, ng/L & 2,200 & 1,615 & 1,543 & 2,182 & 3,798 & $<0.001$ \\
\hline & $(775-5,223)$ & $(570-3,939)$ & $(534-4,138)$ & $(619-4,867)$ & $(1,699-7,279)$ & \\
\hline \multicolumn{7}{|l|}{ Arterial access, $\mathrm{n}(\%)$} \\
\hline Radial & $2,640(85.1)$ & $702(88.6)$ & $663(86.7)$ & $647(83.3)$ & $628(80.9)$ & $<0.001$ \\
\hline Femoral & $464(14.9)$ & $89(11.2)$ & $102(13.3)$ & $128(16.5)$ & $145(18.7)$ & $<0.001$ \\
\hline Brachial & $6(0.2)$ & $1(0.1)$ & $0(0)$ & $2(0.2)$ & $3(0.4)$ & 0.342 \\
\hline GPIIb/IIla medication, n (\%) & $2,016(65.2)$ & $506(64.1)$ & $483(63.5)$ & $487(63.2)$ & $540(69.9)$ & 0.016 \\
\hline Contrast volume, mL & $140(110-180)$ & $140(100-170)$ & $140(100-170)$ & $140(100-170)$ & $150(120-200)$ & $<0.001$ \\
\hline TIMI flow pre-PCI, n (\%) & & & & & & \\
\hline
\end{tabular}


Coelho-Lima et al.

Pre-reperfusion hs-cTnT predicts mortality in STEMI

\begin{tabular}{|c|c|c|c|c|c|c|}
\hline 1 & $136(4.5)$ & $35(4.6)$ & $28(3.8)$ & $44(5.8)$ & $29(3.9)$ & 0.195 \\
\hline 2 & $275(9.2)$ & $68(8.9)$ & $72(9.8)$ & 82 (10.9) & $53(7)$ & 0.066 \\
\hline 3 & $384(12.8)$ & $71(9.3)$ & $120(16.3)$ & $118(15.7)$ & $75(10)$ & $<0.001$ \\
\hline Thrombectomy & $1,866(60.2)$ & $513(64.8)$ & $462(60.6)$ & $441(57)$ & $450(58.2)$ & 0.009 \\
\hline \multicolumn{7}{|l|}{ Number of stents } \\
\hline 0 & $174(5.6)$ & $25(3.1)$ & $43(5.6)$ & $48(6.2)$ & $58(7.5)$ & 0.002 \\
\hline 1 & 1,707 (54.8) & 476 (59.9) & $441(57.6)$ & $420(54.1)$ & $370(47.6)$ & $<0.001$ \\
\hline 2 & $870(27.9)$ & $207(26.1)$ & $202(26.4)$ & $223(28.7)$ & $238(30.6)$ & 0.152 \\
\hline 3 & $266(8.5)$ & $67(8.4)$ & $56(7.3)$ & $64(8.2)$ & $79(10.2)$ & 0.242 \\
\hline$>3$ & $95(3.1)$ & $19(2.4)$ & $23(3)$ & $22(2.8)$ & $31(4)$ & 0.307 \\
\hline \multicolumn{7}{|l|}{ Intra-procedural complications } \\
\hline Coronary slow flow & $59(1.9)$ & $7(0.9)$ & $16(2.1)$ & $11(1.4)$ & $25(3.2)$ & 0.005 \\
\hline Coronary dissection & $37(1.2)$ & $14(1.8)$ & $7(0.9)$ & $11(1.4)$ & $5(0.6)$ & 0.170 \\
\hline Direct current cardioversion & $26(0.8)$ & $7(0.9)$ & $6(0.8)$ & $7(0.9)$ & $6(0.8)$ & 0.989 \\
\hline \multicolumn{7}{|l|}{ TIMI flow post-PCI, $\mathrm{n}(\%)$} \\
\hline 0 & $72(2.4)$ & $16(2.1)$ & $18(2.4)$ & $16(2.1)$ & $22(3)$ & 0.642 \\
\hline 1 & $30(1)$ & $5(0.6)$ & $3(0.4)$ & $8(1.1)$ & $14(1.9)$ & 0.022 \\
\hline 2 & $123(4.1)$ & $9(1.2)$ & $22(3)$ & $30(4)$ & $62(8.4)$ & $<0.001$ \\
\hline 3 & $2,776(92.5)$ & $743(96.1)$ & $693(94.2)$ & $700(92.8)$ & $640(86.7)$ & $<0.001$ \\
\hline \multicolumn{7}{|l|}{ Outcome } \\
\hline In-hospital mortality, $\mathrm{n}(\%)$ & $94(3)$ & $4(0.5)$ & $14(1.8)$ & $18(2.3)$ & $58(7.5)$ & $<0.001$ \\
\hline Overall mortality, n (\%) & $509(16.4)$ & $69(8.7)$ & $113(14.8)$ & $141(18.1)$ & $186(23.9)$ & $<0.001$ \\
\hline
\end{tabular}

Abbreviations: BP, blood pressure; CABG, coronary artery bypass graft; CAD, coronary artery disease; cTnT, cardiac troponin T; GP IIb/IIIa, glycoprotein IIb/IIIa; hs-cTnT, high sensitivity cardiac troponin T; IQR, interquartile range; MI, myocardial infarction; PCI, percutaneous coronary intervention; TIMI, thrombolysis in myocardial infarction angiographic score. 


\section{Coelho-Lima et al.}

Pre-reperfusion hs-cTnT predicts mortality in STEMI

Supplemental table 4. Baseline clinical characteristics of the study population according to $12 \mathrm{~h}$ post-reperfusion hs-cTnT quartiles.

\begin{tabular}{|c|c|c|c|c|c|c|}
\hline Variable & Entire cohort & $\begin{array}{l}\text { Lowest } 12 \mathrm{~h} \text { hs- } \\
\text { cTnT quartile } \\
\text { (<776 ng/L) }\end{array}$ & $\begin{array}{c}2^{\text {nd }} 12 \mathrm{~h} \text { hs-cTnT } \\
\text { quartile } \\
(776-2,200 \mathrm{ng} / \mathrm{L})\end{array}$ & $\begin{array}{c}3^{\text {rd }} 12 \mathrm{~h} \text { hs-cTnT } \\
\text { quartile } \\
(2,201-5,221 \\
\mathrm{ng} / \mathrm{L})\end{array}$ & $\begin{array}{c}4^{\text {th }} 12 \mathrm{~h} \text { hs-cTnT } \\
\text { quartile } \\
\text { (>5,221 ng/L) }\end{array}$ & $p$ value \\
\hline Sample size, $\mathrm{n}(\%)$ & 3,110 & 778 & 779 & 776 & 777 & \\
\hline Gender (male), n (\%) & $2,211(71)$ & $536(68.9)$ & $533(68.4)$ & $552(71.1)$ & $589(75.8)$ & 0.005 \\
\hline Age [years, mean (SD)] & $62.9(12.7)$ & $61.6(12.1)$ & $62.4(12.9)$ & $62.6(12.8)$ & $64.9(12.8)$ & $<0.001$ \\
\hline \multicolumn{7}{|l|}{ Risk factors, n (\%) } \\
\hline \multicolumn{7}{|l|}{ Smoking status } \\
\hline Never smoked & $781(26.7)$ & $181(24.8)$ & $190(25.8)$ & $207(28.2)$ & $203(28)$ & 0.368 \\
\hline Ex-smoker & $813(27.8)$ & $203(27.8)$ & $183(24.8)$ & $203(27.7)$ & $224(30.9)$ & 0.085 \\
\hline Current smoker & $1,335(45.6)$ & $347(47.5)$ & $364(49.4)$ & $324(44.1)$ & $299(41.2)$ & 0.009 \\
\hline Family history of CAD & $1,361(46.1)$ & $347(47.1)$ & $351(47)$ & $354(48.2)$ & $309(42)$ & 0.075 \\
\hline Hypertension & $1,434(46.1)$ & $365(46.9)$ & 365 (46.9) & $343(44.2)$ & $361(46.5)$ & 0.670 \\
\hline Diabetes Mellitus & $393(12.8)$ & $102(13.3)$ & $96(12.4)$ & $91(11.8)$ & $104(13.5)$ & 0.724 \\
\hline Hypercholesterolemia & $1,216(39.1)$ & $321(41.3)$ & $317(40.7)$ & $300(38.7)$ & $278(35.8)$ & 0.111 \\
\hline Obesity & $807(28.2)$ & $211(29.4)$ & $188(26.1)$ & $223(31.1)$ & $185(26)$ & 0.074 \\
\hline \multicolumn{7}{|l|}{ Medical history of CAD, $n(\%)$} \\
\hline Previous angina & $529(17.1)$ & $147(19.2)$ & $132(17.1)$ & $128(16.6)$ & $122(15.7)$ & 0.311 \\
\hline Previous MI & $321(10.4)$ & $98(12.8)$ & 76 (9.9) & 69 (8.9) & $78(10.1)$ & 0.075 \\
\hline Previous $\mathbf{P C l}$ & $201(6.5)$ & $57(7.4)$ & $50(6.4)$ & $46(6)$ & $48(6.2)$ & 0.690 \\
\hline Previous CABG & $56(1.8)$ & $25(3.2)$ & $13(1.7)$ & $14(1.8)$ & $4(0.5)$ & 0.001 \\
\hline \multicolumn{7}{|l|}{ Clinical characteristics on admission } \\
\hline Heart rate, bpm [median (IQR)] & $75(63-88)$ & $73(61-87)$ & $75(63-88)$ & $74(63-90)$ & $77(65-90)$ & 0.098 \\
\hline Systolic BP, mmHg [median (IQR)] & $127(109-147)$ & $127(110-145)$ & $128(110-148)$ & $127(110-150)$ & $125(105-143)$ & 0.019 \\
\hline
\end{tabular}


Pre-reperfusion hs-cTnT predicts mortality in STEMI

\begin{tabular}{|c|c|c|c|c|c|c|}
\hline Cardiogenic shock, $\mathrm{n}(\%)$ & $128(4.1)$ & $27(3.5)$ & $21(2.7)$ & $34(4.4)$ & $43(5.6)$ & 0.030 \\
\hline \multicolumn{7}{|l|}{ Admission route, $\mathrm{n}(\%)$} \\
\hline Emergency services & $2,264(72.7)$ & $549(70.6)$ & $578(74.2)$ & $556(71.6)$ & $579(74.5)$ & 0.222 \\
\hline Inter-hospital transfer & $849(27.3)$ & $229(29.4)$ & $201(25.8)$ & $220(28.4)$ & $198(25.5)$ & 0.222 \\
\hline Door to balloon, min [median (IQR)] & $23(18-33)$ & $24(18-34)$ & $23(17-33)$ & $23(17-33)$ & $23(18-33)$ & 0.266 \\
\hline $\begin{array}{l}\text { Onset to reperfusion, } \min \\
\text { [median (IQR)] } \\
\text { Infarct location, } n(\%)\end{array}$ & $168(117-267)$ & $160(113-263)$ & $169(118-269)$ & $174(118-277)$ & $172(119-255)$ & 0.185 \\
\hline Anterior & $1,207(39.3)$ & $258(33.7)$ & $269(35.1)$ & $272(35.4)$ & $406(52.5)$ & $<0.001$ \\
\hline \multicolumn{7}{|l|}{ Biochemical tests [median (IQR)] } \\
\hline Admission haemoglobin, $\mathrm{g} / \mathrm{dL}$ & $\begin{array}{c}13.8 \\
(12.6-14.9)\end{array}$ & $13.8(12.4-14.9)$ & $13.8(12.6-14.8)$ & $13.8(12.6-14.9)$ & $13.9(12.6-15.1)$ & 0.194 \\
\hline Admission creatinine, $\mu \mathrm{mol} / \mathrm{L}$ & $81(69-96)$ & $79(67-94)$ & $77(67-93)$ & $82(69-94)$ & $85(72-100)$ & $<0.001$ \\
\hline Admission hs-cTnT, ng/L & $\begin{array}{c}121 \\
(39-515)\end{array}$ & $71(28-176)$ & $102(34-472)$ & $160(44-600)$ & $256(56-1,037)$ & $<0.001$ \\
\hline 12h hs-cTnT, ng/L & $\begin{array}{c}2,200 \\
(775-5,223)\end{array}$ & $\begin{array}{c}331 \\
(154-551)\end{array}$ & $\begin{array}{c}1,344 \\
(1,041-1,740)\end{array}$ & $\begin{array}{c}3,377 \\
(2,744-4,143)\end{array}$ & $\begin{array}{c}8,433 \\
(6,480-10,000)\end{array}$ & $<0.001$ \\
\hline \multicolumn{7}{|l|}{ Arterial access, $\mathrm{n}(\%)$} \\
\hline Radial & $2,640(85.1)$ & $648(83.4)$ & $666(85.6)$ & $661(85.3)$ & $664(85.5)$ & 0.583 \\
\hline Femoral & $464(14.9)$ & $126(16.2)$ & $112(14.4)$ & $112(14.5)$ & $112(14.4)$ & 0.686 \\
\hline Brachial & $6(0.2)$ & $3(0.4)$ & $0(0)$ & $2(0.3)$ & $1(0.1)$ & 0.342 \\
\hline GPIIb/IIla medication, n (\%) & $2,016(65.2)$ & $487(63.2)$ & $492(63.6)$ & $514(66.4)$ & $521(67.6)$ & 0.200 \\
\hline Contrast volume, $\mathrm{mL}$ & $140(110-180)$ & $130(100-160)$ & $140(110-170)$ & $150(110-180)$ & $150(120-190)$ & $<0.001$ \\
\hline \multicolumn{7}{|l|}{ TIMI flow pre-PCI, n (\%) } \\
\hline 0 & $136(4.5)$ & $402(53.7)$ & $514(69)$ & $609(81.6)$ & $683(89.5)$ & $<0.001$ \\
\hline 1 & $275(9.2)$ & $52(7)$ & $40(5.4)$ & $27(3.6)$ & $17(2.2)$ & $<0.001$ \\
\hline
\end{tabular}


Coelho-Lima et al.

Pre-reperfusion hs-cTnT predicts mortality in STEMI

\begin{tabular}{|c|c|c|c|c|c|c|}
\hline 2 & $384(12.8)$ & $107(14.3)$ & $87(11.7)$ & $48(6.4)$ & $33(4.3)$ & $<0.001$ \\
\hline 3 & $1,866(60.2)$ & $187(25)$ & $104(14)$ & $62(8.3)$ & $30(3.9)$ & $<0.001$ \\
\hline Thrombectomy & & $392(50.6)$ & $452(58.3)$ & $487(62.8)$ & $534(69)$ & $<0.001$ \\
\hline Number of stents & $174(5.6)$ & & & & & \\
\hline 0 & $1,707(54.8)$ & $45(5.8)$ & $39(5)$ & $61(7.9)$ & $28(3.6)$ & 0.003 \\
\hline 1 & $870(27.9)$ & $452(58.1)$ & $424(54.4)$ & $412(53.1)$ & 419 (53.9) & 0.203 \\
\hline 2 & $266(8.5)$ & $206(26.5)$ & $222(28.5)$ & $219(28.2)$ & $222(28.6)$ & 0.770 \\
\hline 3 & $95(3.1)$ & $59(7.6)$ & $72(9.2)$ & $57(7.3)$ & $78(10)$ & 0.168 \\
\hline$>3$ & & $16(2.1)$ & $22(2.8)$ & $26(3.4)$ & $30(3.9)$ & 0.193 \\
\hline Intra-procedural complications & $59(1.9)$ & & & & & \\
\hline Coronary slow flow & $37(1.2)$ & $11(1.4)$ & $16(2.1)$ & $18(2.3)$ & $14(1.8)$ & 0.602 \\
\hline Coronary dissection & $26(0.8)$ & $9(1.2)$ & $9(1.2)$ & $10(1.3)$ & $9(1.2)$ & 0.993 \\
\hline Direct current cardioversion & & $8(1)$ & $4(0.5)$ & $6(0.8)$ & $8(1)$ & 0.634 \\
\hline TIMI flow post-PCI, n (\%) & $72(2.4)$ & & & & & \\
\hline 0 & $30(1)$ & $16(2.1)$ & $18(2.4)$ & $23(3.1)$ & $15(2)$ & 0.528 \\
\hline 1 & $123(4.1)$ & $9(1.2)$ & $5(0.7)$ & $12(1.6)$ & $4(0.5)$ & 0.138 \\
\hline 2 & $2,776(92.5)$ & $14(1.9)$ & $26(3.5)$ & $33(4.4)$ & $48(6.4)$ & $<0.001$ \\
\hline 3 & $\begin{array}{c}13.8 \\
(12.6-14.9)\end{array}$ & $717(94.8)$ & $699(93.4)$ & $679(90.9)$ & $680(91)$ & 0.007 \\
\hline \multicolumn{7}{|l|}{ Outcome } \\
\hline In-hospital mortality, n (\%) & $94(3)$ & $24(3.1)$ & $18(2.3)$ & $23(3)$ & $26(3.3)$ & 0.661 \\
\hline Overall mortality, $\mathrm{n}(\%)$ & $509(16.4)$ & $123(15.8)$ & $119(15.3)$ & $110(14.2)$ & $154(19.8)$ & 0.016 \\
\hline
\end{tabular}

Abbreviations: BP, blood pressure; CABG, coronary artery bypass graft; CAD, coronary artery disease; cTnT, cardiac troponin T; GP IIb/IIIa, glycoprotein IIb/IIIa; hs-cTnT, high sensitivity cardiac troponin T; IQR, interquartile range; MI, myocardial infarction; PCI, percutaneous coronary intervention; TIMI, thrombolysis in myocardial infarction angiographic score. 


\section{REFERENCES (SUPPLEMENTS)}

1. Stamatelopoulos K, Mueller-Hennessen M, Georgiopoulos G, Sachse M, Boeddinghaus J, Sopova K, et al. Amyloid-beta (1-40) and Mortality in Patients With Non-ST-Segment Elevation Acute Coronary Syndrome: A Cohort Study. Ann Intern Med. 2018;168(12):855-65.

2. Fox KA, Fitzgerald G, Puymirat E, Huang W, Carruthers K, Simon T, et al. Should patients with acute coronary disease be stratified for management according to their risk? Derivation, external validation and outcomes using the updated GRACE risk score. BMJ Open. 2014;4(2):e004425. 
STROBE Statement — Checklist of items that should be included in reports of cohort studies

\begin{tabular}{|c|c|c|c|}
\hline & $\begin{array}{c}\text { Item } \\
\text { No }\end{array}$ & Recommendation & Page No \\
\hline \multirow[t]{2}{*}{ Title and abstract } & 1 & $\begin{array}{l}\text { (a) Indicate the study's design with a commonly used term in the title or } \\
\text { the abstract }\end{array}$ & 3 \\
\hline & & $\begin{array}{l}\text { (b) Provide in the abstract an informative and balanced summary of what } \\
\text { was done and what was found }\end{array}$ & 3 \\
\hline \multicolumn{4}{|l|}{ Introduction } \\
\hline Background/rationale & 2 & $\begin{array}{l}\text { Explain the scientific background and rationale for the investigation being } \\
\text { reported }\end{array}$ & 4 \\
\hline Objectives & 3 & State specific objectives, including any prespecified hypotheses & 5 \\
\hline \multicolumn{4}{|l|}{ Methods } \\
\hline Study design & 4 & Present key elements of study design early in the paper & 6 \\
\hline Setting & 5 & $\begin{array}{l}\text { Describe the setting, locations, and relevant dates, including periods of } \\
\text { recruitment, exposure, follow-up, and data collection }\end{array}$ & $5 / 6$ \\
\hline \multirow[t]{2}{*}{ Participants } & 6 & $\begin{array}{l}\text { (a) Give the eligibility criteria, and the sources and methods of selection of } \\
\text { participants. Describe methods of follow-up }\end{array}$ & $5 / 6$ \\
\hline & & $\begin{array}{l}\text { (b) For matched studies, give matching criteria and number of exposed and } \\
\text { unexposed }\end{array}$ & N/A \\
\hline Variables & 7 & $\begin{array}{l}\text { Clearly define all outcomes, exposures, predictors, potential confounders, } \\
\text { and effect modifiers. Give diagnostic criteria, if applicable }\end{array}$ & $5 / 6$ \\
\hline $\begin{array}{l}\text { Data sources/ } \\
\text { measurement }\end{array}$ & $8^{*}$ & $\begin{array}{l}\text { For each variable of interest, give sources of data and details of methods } \\
\text { of assessment (measurement). Describe comparability of assessment } \\
\text { methods if there is more than one group }\end{array}$ & 6 \\
\hline Bias & 9 & Describe any efforts to address potential sources of bias & \\
\hline Study size & 10 & Explain how the study size was arrived at & $5 / 10$ \\
\hline Quantitative variables & 11 & $\begin{array}{l}\text { Explain how quantitative variables were handled in the analyses. If } \\
\text { applicable, describe which groupings were chosen and why }\end{array}$ & $7 / 8$ \\
\hline \multirow[t]{5}{*}{ Statistical methods } & 12 & $\begin{array}{l}\text { (a) Describe all statistical methods, including those used to control for } \\
\text { confounding }\end{array}$ & $7 / 8$ \\
\hline & & (b) Describe any methods used to examine subgroups and interactions & $7 / 8$ \\
\hline & & (c) Explain how missing data were addressed & 8 \\
\hline & & (d) If applicable, explain how loss to follow-up was addressed & N/A \\
\hline & & (e) Describe any sensitivity analyses & 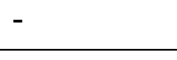 \\
\hline \multicolumn{4}{|c|}{ (2) } \\
\hline Participants & $13^{*}$ & $\begin{array}{l}\text { (a) Report numbers of individuals at each stage of study - eg numbers } \\
\text { potentially eligible, examined for eligibility, confirmed eligible, included } \\
\text { in the study, completing follow-up, and analysed } \\
\text { (b) Give reasons for non-participation at each stage } \\
\text { (c) Consider use of a flow diagram }\end{array}$ & 10 \\
\hline Descriptive data & $14^{*}$ & $\begin{array}{l}\text { (a) Give characteristics of study participants (eg demographic, clinical, } \\
\text { social) and information on exposures and potential confounders } \\
\text { (b) Indicate number of participants with missing data for each variable of } \\
\text { interest } \\
\text { (c) Summarise follow-up time (eg, average and total amount) }\end{array}$ & $\begin{array}{l}10 / 24 \\
4 \\
\text { (Appendix) } \\
11\end{array}$ \\
\hline Outcome data & $15^{*}$ & Report numbers of outcome events or summary measures over time & Figure 2 \\
\hline
\end{tabular}




\begin{tabular}{|c|c|c|c|}
\hline Main results & 16 & $\begin{array}{l}\text { (a) Give unadjusted estimates and, if applicable, confounder-adjusted estimates and their } \\
\text { precision (eg, } 95 \% \text { confidence interval). Make clear which confounders were adjusted for } \\
\text { and why they were included } \\
\text { (b) Report category boundaries when continuous variables were categorized } \\
\text { (c) If relevant, consider translating estimates of relative risk into absolute risk for a } \\
\text { meaningful time period }\end{array}$ & $11 / 12$ \\
\hline Other analyses & 17 & $\begin{array}{l}\text { Report other analyses done - eg analyses of subgroups and interactions, and sensitivity } \\
\text { analyses }\end{array}$ & $12 / 13$ \\
\hline \multicolumn{4}{|l|}{ Discussion } \\
\hline Key results & 18 & Summarise key results with reference to study objectives & 14 \\
\hline Limitations & 19 & $\begin{array}{l}\text { Discuss limitations of the study, taking into account sources of potential bias or imprecision. } \\
\text { Discuss both direction and magnitude of any potential bias }\end{array}$ & 17 \\
\hline Interpretation & 20 & $\begin{array}{l}\text { Give a cautious overall interpretation of results considering objectives, limitations, } \\
\text { multiplicity of analyses, results from similar studies, and other relevant evidence }\end{array}$ & $15 / 16$ \\
\hline Generalisability & 21 & Discuss the generalisability (external validity) of the study results & 17 \\
\hline \multicolumn{4}{|c|}{ Other information } \\
\hline Funding & 22 & $\begin{array}{l}\text { Give the source of funding and the role of the funders for the present study and, if } \\
\text { applicable, for the original study on which the present article is based }\end{array}$ & 9 \\
\hline
\end{tabular}

*Give information separately for exposed and unexposed groups.

Note: An Explanation and Elaboration article discusses each checklist item and gives methodological background and published examples of transparent reporting. The STROBE checklist is best used in conjunction with this article (freely available on the Web sites of PLoS Medicine at http://www.plosmedicine.org/, Annals of Internal Medicine at http://www.annals.org/, and Epidemiology at http://www.epidem.com/). Information on the STROBE Initiative is available at http://www.strobe-statement.org. 